\title{
's Graven domein te Nieuwpoort
}

\section{STICHTING VAN'S GRAVEN DOMEIN TE NIEUWPOORT}

Tot ver in de middeleeuwen bleef de IJzermonding een diepe golf, die zich tot in de omstreken van het oude Vleteren (heden West- en Oostvleteren) uitstrekte en die door de historici genoemd wordt «golf van Loo», naar het eilandje van die naam, dat er in lag ${ }^{1}$. De aanslibbing en de landwinning vorderden er evenwel met rasse schreden. De beide oevers van de zeeboezem werden geleidelijk ingepolderd, tot ten slotte slechts een langwerpige inham overbleef ${ }^{2}$. Van 1050 af ontstonden in het bekken van den beneden IJzer de talrijke dorpen, waarvan de plaatsnaam eindigt op -kapelle of -kerke ${ }^{3}$. Toen werden ook opgericht de verschillende kustabdijen ${ }^{4}$, wier bedrijvigheid ten zeerste door de graven van Vlaanderen gesteund zou worden. Diederik en Filips van den Elzas verdeelden onder deze nieuwe kloostergemeenschappen de schorren, die voortdurend nog in den IJzerinham droog kwamen, met de opdracht er door indijking weide- en akkergrond van de maken 5 . De bisschop van Terwaan van z:jn kant vertrouwde de zielzorg over de nieuwe dorpen eveneens aan de ijverige monniken toe. Aldus

(1) R, BLANCHARD : La Flandre. Etude géographique de la plaine flamande en France, Pelgirue et Hollande, 1906, p. 158.

(2) ldem, p. 167 .

(3) J. DHONDT: Het Ontstam van het rorstendom Thanderen. Revue belge de philologie ef d'histoire, t. XXI (1942), p. 70, nota 1 .

(4) De abdij Sint-Pieter te ondenburk werd gesticht in 1084 an het I.Jzerastuarium, dat nar het $\mathrm{Zwin}$ lifin, fle abdij van de Duinen in 1107 in de duinenketen ten oosten van Veune en de abdij SintNiklas in 1120 te Teune Zie: HARICLT: Tita Amulfi episcopi suessionersis, M.G.H., SS., t. XV-2, 1). 892 ; F. VAN IOH PUTWE: cronica et cartularinm monasterii de Dunis, Brugis, 1864, t. I, py). IV (n 3; F. TAN I)E PTT'LE et C. L. CARTON : Chronica et cartularinm (1)batien s. Nicolat Funensis (1120-135y). Brugis, 18-49. Introduction.

(5) H. COPTIETERS-S'TOCKHOVE : Régestes de Thierri d'Alsuce, comte ae Flandie (Ann, soc. dhist. de Gand, t. IV, 1902), lrassim: IDEM : Régestes a.e Philippe d'Alsace, comte de Flandre (Ibid., t. VII, 1906), passim. 
gaf hij in 1135 aan de abdij Sint-Niklaas van Veurne de zielzorg over de parochiën Oostduinkerke, Wulpen en Ramskapelle ${ }^{6}$. Op dat ogenblik reeds was de linkeroever van de IJzermonding, waaraan deze dorpen gelegen waren, beschermd door het «Zandhoofd», een natuurlijken dijk, bestaande uit een reeks hoge duinen en zandbanken, waarvan de aanslibbingen steeds aangroeiden $`$. Naast de abdij Sint-Niklaas waren in dit duinenlandschap ook de andere kustabdijen werkzaam. De abdij van Sint-Winnoksbergen had er sinds 1100 een schapenweide in gebruik ${ }^{8}$, terwijl her vrouwenklooster van Burburg er sedert 1108 het gedeelte palende aan Ramskapelle bezat ${ }^{9}$. Meer stroomopwaarts was het de abdij van de Duinen, die er ton tijde van den groten abt Idesbald (1155-'67) uitgestrekte terreinen foldergrond wist te winnen ${ }^{10}$ en er naderhand haar bekende hoeven, o.a. «de Grote Hemme» te Pervijze en «Ailaertshuizen》 te Wulpen, zou oprichten ${ }^{11}$.

(6) F. VAN DE PUTTE et C. CARTON, Chronica et cartularimm abbatide s. Nicolat Fumensis, ol). (it., D. 56. - Oosiduinkerke droger aanvankelijk de naam inunapaplia.

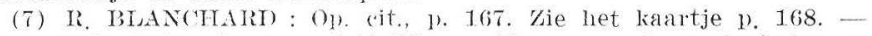
Deze onde keten is nog duidelijk merkbar op de geologische en topographische kaarten. Zice te topographische kaart ran Belgiēe of schat $1 / 20.000$, nitgegeren door het militair cartographisch insti nut te Brussel. Blad Nieuport $(12 / 5), 1934$. De hoogtelijnen $t$ en 5 hidien het oude Zandhootd aan.

(8) « Terram centum orium in Sandasovad 》. Bekrachtigingsoorkonde ran omstreeks 1107 nopens een uitwisseling van gronden tussen de abdij van sint-Winnoksbergen en Rober: II (gestorven in 1093). A. PRUTOST: Ghronique et cartulaire de l'abbaye de Bergues-saint-Winnoc. Bruges, $1875-78$, t. I, 1) 86. Het bezit ran een « terram in Santshovede $101 m$ centum ovibus » wordt in 1184 hekrachtigd. Ibid., p. 194.

(9) «..novam terram, nomine sandeshove, que per jactum maris iam crevit, et quicquid in posterum accrescet, super flurium Ysare sitam, sancte Marie in Broburg, in usum sauctimonialium ibidem reo famulantium, integre denavimus 》. T. GLLLIOP'SS-TAN SETE. REN : Coutumes de la ville et du port de Nieuport, in Coutumes de la ville et chatellenie the Funes, t. VI, Bruxelles, 1901, 1. $1+1$. nr. 1. Oorkonde van 27 Mei 1108. Onjuist gedateerd 1112. Gift van wrataf Robert II van Jerusalem.

(10) 1 . FRIs et $A$. HETSS: Les granges monumentales des an(iennes abbayes des Dunes et Ther Doest dans la Flandre maritime (Allle siècle). Notes historiques par $\mathrm{Mr}$. V. Fris. Etules darchéologie pittoresque pai A. Hejns. Gand, 1905, p. 9.

(11) J. DE CUYPER : Wording lan de Hemme, het groot nithof wan de Dninenablij te Ramscapelle (Nieuwpoost). Ann. Soc. Em, de Bruges, 1929 , t. 72 , p. $80-98$. 
Typisch voor het statuut van de «nieuwe stad》 is vooral het fiskiai regine. De keure van 1163 vermeldt niet uitdrukkelijk de toekenning aan de burgers van de vrije beschikking over de afgestane percelen gronds, maar heeft het alleen over de «teloneum de terra» 19 . Wat hiermee juist bedoeld werd, is niet duidelijk. Ofwel was het de eigenlijke grondcijns ten bedrage van 1 denier de roede en 's gravenlandschuld genoemd in latere teksten 20 , ofwel was het eenvoudig de tol, die op de verhandeling van gronden geheven werd ${ }^{21}$. Wat er ook van zij, de grondcijns te Nieuwpoort was niet juridisch bedoeld zoals het recognitiegeld, dat in de grote Vlaamse gemeenten op den bodem drukte en afgekocht kon worden 22 , maar wel fiskaal. Hij was voor de graaf, die grondheer wou blijven, een bron van inkomsten.

De keure schenki ook aan ieder burger tolvrijdom in zijn eigen stad, mits betaling aan den vorst ieder jaar op Sint-Brixisdag (13 November) van 4 denieren, een recognitiegeld, dat naderhand 《stalpenning》 of 《estallaige» genoemd werd ${ }^{23}$. Ze formuleert evenwel enkele restricties op dit voornaam voorrecht, wat eveneens als een erkenning van de grafelijke prerogatieven in zake tolheffing begrepen moet worden. Aldus handhaaft ze de tollen geheven op de verhandeling van pluimwaren en misschien,

A. LALLEMAND et I)r. W. DE VRFESE : Documents fondamentant de l'histoire de Belgique. Chartes de coutumes, édits et actes diplomatiques avec commentaires et annotations. Liége, 1913, p. 27, art. 14 van de keure.

(19) «Concessi etiam opichnis meis de novo opido, quoß quicumque ibi manserit, ab omni teloneo, nisi sit de terra vel de plumis liber erit, sed teloneario in die Sancti Briccii singulis annis quatuor denarios dabit ». Keure van Nieuwport ran 1163 , art. 15. I. GIL LTODTS-VAN SEVEREN : Coutumes... de Nieuport. Op. cit., p. 144. (20) Zie hierboren nota 13.

(21) « Qui terram rendicierit, quatuor denarios dabit, et qui enerit quatuor ». Keure van Nieuwpoort van 1163, art. 23. I. GMIIODTSVAN SEVEREN : Coutumes... de Nieuport, op. cit., p. 145.

(22) Reeds in het begin vau de 12 de eeuw vercween aldus te Gent de « census de mensionibus », warschijnlijk dool: afkoop. FR. BLoCKMANS : Het Gentsche Stadspatriciaat tot omstreeks 1302, in Werken uitgegeven door de Fac. van Wijsbegeerte en Letteren, Rijksuniversiteit te Gent:- Antwerpen en 's Gravenhage, 1938, p. 118-135. 
zoals gezegd, van gronden ${ }^{24}$. Ook legt ze een kleinen tol op de fabricatie en op den verkoop van inheems bier en brood, alsmede op de verhandeling van uitheems bier en mede ${ }^{25}$ en bestraft de ontduikers hiervan ${ }^{26}$. Op den verkoop van wijn in de herbergen integendeel legt ze een tol, die in natura geheven, een fiskaal doel moet hebben gehad en misschien te vereenzelvigen is met de latere 《forage», een grafelijke belasting 27 .

Filips van den Elzas schijnt in feite met de stichting

(23) Zie hierboven nota 19 . Dat de cijns van 4 d. de « stalpenning » was, blijkt uit che heffing ervan te Lombardsijde in 1313, toen dit recht reeds te Nieuwpoort afgeschaft was : " Dit zijn degheene lie hare stalpenninghe ghelcien te Lombardie oup Sinte Brixsis dach, curte die nie ne coemt oup Sinte Brixsisdach mit 4 d. par., hie es al 't jaer ontrryet van zinen porterschepe $\gg$. R. DE BEAUCOURT DE NOORTVELDE : Nieuport. Documents historiques, t. 2, p. 161. "Dit es de boec van den hofsteden]ande van der Nieuwerpoort ». Kadaster van 1313.

$(24)$ 《 (21) Lectum vendens duos dabit denarios, emens duos. (22) Qui emit pelu (Id est pulna, bijgevoegd), obolum dabit, et qui rendit obolum. - (23) Qui terram vendiderit, quatuor denarios dabit, et qui emerit quatuor. -- (24) Qui extraneus lectum sine plumis (Id est ticam, bijgeroegd), rendiderit, unum denarium dabit, et qui emerit unum ». L. GILLIODTS-VAN SEVEREN : Coutumes de la wille et du port de Nieuport, op. eit., p. 145. Artikels 21 tot 24 van de keure van 1163. Art, 24 gold naturlijk alleen voor de vreemdelingen. We vermelden het met het oog op de rerklaring van artikels 21 en 22.

(25) « Quicumque panes renales fecerit, in die sabbati, panem de obolo dabit. 》 Idem, ibidem, p. 144, art. 18.

"Quicumque cervisiam fecerit, de una eervisia duos denarios whet 》. Idem, ibidein, p. 144, art. 17.

«Et quicunque extraneam cervisiam vel extraneum medonem vendiderit, de rase uno denariatam unam debet $»$ L. GILLIODTS-VAN SEVEREN, op cit., p. 144, art. 17. - Voorde rreemdelingen gold dan nog de rolgende tol : "Qui extraneus medonem vel cervisiam adduxerit, de vase uno denarium unum debet ». Ibidem.

(26) « Si de teloneo panis rel cervisie aliquis acusatus fuerit, iuramento sine reprehensione se excusabit ». Idem, ibidem, art. 19. Veelbetekenend is het feit dat de woorden panis vel cervisie tussen den tekst ingelast. werden.

$(2 \tau)$ 《 Qniconque rinum rendiderit more taberne, sextarium vini dabit de uno rase ». Ibigen, art. 20. - Voor de vreemdelingen gold nog volgende tol : "Et qui extraneus vinum adduxerit, de uno vase 4ratuor denarios dabit 》. Ihidem. - Van de « forage 》 wordt voor het eerst gewag gemaakt in 1269 : « Et si doivent cil de Lombardej paier a nous et a nos hoirs singneurs de Flandres, en non de tonlieu, forage, estallaige, et autres droitures en la ville de Lombardie, comme li bourgois de Noefport ». Appointement van gravin Margaretha over de juridische betrekkingen tussen Nieuwpoort en Lombardsijde, art. 11. L. GILLIODTS-VAN SEVEREN : coutumes de la ville et chatellevie de furnes, t. IV. Coutumes de Lombardside, Loo et. Poperinghe, p. $14, \mathrm{n}^{\circ} \mathrm{II}$. 
van Nieuwpoort niet alleen de kolonisatie, maar ook het handelsverkeer te hebben willen bevorderen. Dit blijkt duidelijk uit de formulering in de keure van de talrijke door den landsheer op de markt of in de haven geheven tollen ${ }^{28}$. Alhoewel dit tarief met het eigenlijk statuut van de nieuwe stad heel weinig te maken had, beslaat het toch gans de tweede helft van het Nieuwpoorts handvest ${ }^{29}$. De opsomming van de verschillende aan tolheffing onderworpen landbouw-, veeteelt- en visserijproducten verraadt misschien zelfs een poging van den toekomstigen graaf om van Nieuwpoort een plaatselijke markt van agrarische voortbrengselen en vis te maken ${ }^{30}$. Gelegen in een polderstreek, waarvan de ontginning pas een aanvang nam, was de plaats hiervoor geschikt, temeer daar ze als voorhaven voor het veel oudere Veurne en voor de abdij van de Duinen diende ${ }^{31}$.

Filips voligde in 1168 zijn vader als graaf op, wat hem toeliet zijn plannen verder uit te voeren. Omstreeks 1176 inderdaad ging hij over tot het aanleggen tussen de Venepe, of Veurnsen waterweg, en den IJzer van een verbindingskanaal, dat zowel voor de drainering als voor de binnenscheepvaart diende en aan den oostkant van de nieuwe stad zijn uitmonding had ${ }^{32}$. De «magna sclusa»,

(28) « Omnis extraneus de stabulo dabit obolum in die fori 》. Zie het tarief ran de tollen vervat in de keure, in $\mathrm{I}$. GILLroD's VAN SEVEREN : Coutumes de... Nieuport, op. cit.. pl. 145, 146 en 147.

(29) Dit verklaart wellicht de naam ran de keure « legis justicia ». Zie hierboven nota 16.

(30) R. DEGRYSE : Oude en nieure havens nan het IJzerbek ken in de Middeleenven, in Handelingen van de soc. d'Emulation van Brugge. deel 84 (jaargang 1947, pp. 6-40.), p. 17.

(31) De burgers van Veurne ontvingen in 1176 van Filips ran den Elzas volledigen tolvijicom te Nieuwpoort. I. GILLIONTS-VAN SFVERIN : Coutumes le la ville et chatellerie de Furnes, t. III, p. 23 , no IV. Stuk van 1176 .

$(32)$ « Noverint et presentes et posteri, quod Philippus, comes Flandrie, jussit fieri aqueductum inter Furnes et Dixmuda, inicium habentem ab Ysara et se longius extendentem per diversas terras ». Acte van 1183 waardoor de abdij van Eename recht op schadevergoeding krijgt voor de gedeelten van haar grondbezit, ciie, wegens het aanleggen van het nieuw kanaal tussen Veurne en den IJzer, op last van den graaf onteigend werden. CH. DIOT: Cartulaire de l'abbaye d'Eename. Bruges, 1881, p. 63 , no 68 . - Dit verbindingskanaal moet 
die hij daar deed bouwen, stelde hij in 1184 onder de hoede van de abdij van de Duinen met de opdracht, in geval van zware beschadiging door den vloed, haar met de medewerking en op de kosten van de plaatselijke polderbevolking te doen herstellen ${ }^{33}$. Hij schonk in 1183 aan de abdij Sint-Niklaas te Veurne en aan de O.L.Vrouwkerk te Nieuwpoort ${ }^{34}$, als bron van inkomsten, de heffing van het haringtiend, een geldelijke bijdrage, die de vissers elk jaar na afloop van het haringseizoen te betalen hadden, wat wijst op de definitieve vorming van de Nieuwpoortse parochie 35 . In een schrijven, dat ze hetzelfde

gregraren qureest zijn omstreeks 1176, ogenblik waarop, de graaf aan de burgers ran Veurne te Nieuwpoort rolledigen tolvijolom te limul en te water toestond. Zie nota hierboren.

- De Venepe mondde aanvankelijk uit in den IJzei nabij Pervijze en niet ten westen van Ramskapelle, zoals de zesentiendepuwse chronijkschrijver Pauwel Hesnderyex ten onrechte beweert. Te loop van den IJzer kan dus niet langs de Venepenonding afgeleid geworden zijn, bewering, die we bij denzelfden schrijver vinden. Zie P. HWYNDERYCX : Jaerboeken van Teurne en Teurne-Ambacht, ér. RoNssc. Veurne, 1853, t. I, p. 97. - Voor de vereenzelviging ran de Venepe yie I. DE CUYPER: Wording van de Hemme, het groot withof ran the Duinensabdij te Ramskapelle, op. cit., 1). 83.

(33) « ...eo tenore ut ipsi fratres magnam sclusam sub sua custodia debeant comservare, et quicquid propter maris inondationem que fossafum rumpat, fodiendo refeci, ant uno die ab nno carpentario restaurari potuit, suis impendis reparare. Vero si casa aliquo prefata slusa confractum, nichilomino ad fratrum spectabi industriam vel impensam, sed communi totius populi restaurabitu expensa 》. (oorkonde van 22 Maart 1184. F. VAN DE PUTTE : Cronica et cartulerium monasterii de Dunis, op. cit., XLIX, no 227,1 ). 166.

- De abdij van de Duinen polderde naderhand omheen de shis ren geker aantal gemeten aronds in en richtte gebouwen op. Die wronden hoorden evenwel toe an de abdij van Burburg krachtens pen oorkonde van 1108. Ferst in 1275, na een langdurig geschil, deed de abdij van Burburg afstand van haar rechten ol de\%en bodem. Oortkonde vin 12 Mei 1275 , nar een vidimus van 15 Juli 1275 . Cronicu et catularium monasterii de mmis. Op. cit., 1) 162, no (CCCXVI. Zie ook C. L. CARTON : Cronica abbatum monasterii te Dunis, yat Ad. DE BUIVT. Brugis, 1839, p. 122, sub anno 1275.

(34) Oudste vermelding van de Nieuwpoortse O. L. Yrouwkerk, in 1171 : "ecrlesiam de Nowo Burgo 》. Chronica et cartularium abbutiu sancti ricolai Funensis (FA. F. VAN DE IUTTE et (. L. (ARTON). Hrugis, $18+9$, p. 68.

(35) In 1183 schonk Filips van den Elzas aan de abdij Sint-Niklaas van Veurne het derde gedeelte ran de opbrengst ran het haringtiond te Oostruinkerke en te Nieuwpoort : « Fadem quoque auctoritate, trriam partem decime allecium, quam me favente precicta obtinuit ecclesia, eidem communiendam pia derocione deliberavi. Hanc siquidem decimam a piscatoribus Dunkerke, Noviburgi exigendam et exihendam, ordinatum et statutum est eo jure quo parrochial s. Winnoci 
jaar aan den paus gericht zouden hebben, verklaarden de Nieuwpoortenaars toen reeds sedert meer dan 60 jaar dit tiend regelmatig aan hun parochiale herders te hebben uitgekeerd 36 . Misschien herinnerden ze hiermee aan den tijd, dat ze nog tot een oudere parochie - waarschijnlijk Oostduinkerke - behoorden ${ }^{37}$. Dit zou er dan kunnen op duiden dat Nieuwpoorts eerste bevolking grotendeels uit dit dorpje afkomstig moet geweest zijn 38. Wat er ook van zij, de oorspronkelijke plaatsnaam Zandhoofd kwam reeds kort na 1163 in onbruik. Zolang de tijdgenoten te doen hadden met de nederzetting in wording, gewaagden

suas decimas de re simili reddere debere tenetur $\gg$. I. GLLLODTsVAN SEVERGN : Coutumes de la ville et du port de Nienport, op. (cit., p. 15t, no VII. - De twee ancere derden van het tiend bleven voorbehouden aan den pastoor en den dis van elk van de beide paro(hiēn. Zie betreffende de haringtienden Ir. DEGRYsE : Fuanderens Haringuisscherij in de Hiddeleewuen, in Handelingen ran het Genootschap « Société d'Emulation 》 to Brugge, deel 82, jaargang 1939, pp. 191 à 193 ; R. DEGRYSE : Vuanderens Haringbedriff in de Middeleenwen. Antwerpen, 1944 (Reeks de scicoenen, no 49), pp. 63-70.

(36) « Sanctissimo Patri ac Domino Dei gratia Summo Pontifici universi parochiani de Novo portu pedum oscula heatorum. Yoverit restra veneranda sanctitas, quod nos elemosinam quandam, quae vulgariter decima allecium nuncupatur, ex pia devotione statutam ab antiguo, tripliciter divisam, mam partem scilicet persona parochialis perlesiæ nostre, secundam fabricx ejusdem ecclesia, et terfiam pauperibus a sexagintr annis et amplius elapsis, eisdem videlicet persona, fabrica ef pauperibns solvimus, tam jiberaliter quam libenter. et solvere volumus, in futurum $»$. Brief van 1183, naar cen vidimus van 1235. L. GILLIOITS-YAN SHVEREN : Coutumes de la rille el du port de Vienport, op. cit., p. 153 , no VI. - Dit stuk is verdacht wogens de term Novo Portu, dje er in voorkont en die wel in 1235 , matar nog niet in 1183 in gebruik was. De gegevens, warol het vidimas steunt, kunnen evenwal juist zijn, zelfs indien de zogezegde brinf ran 1183 rals is.

(37) De parochie oostduinkerke ontstond kort nat 1100 onder de naam « Dunacapella ». Zie hierboven nota 6.

(38) De Nieuwpoortse bevolking kan dus niet lierkomstig geweest zijn nit Lombardsijge, dat toen nog niet bestond. Toch werd hierover ef $n$ legende in omloop gebracht : de talrijke ovcrstromingen, alsmede de zogezegde verplaatsing van de IJzelmonding, die eerst ten oosten van Lombardsijgle en daarna ten westen van die plaats (die toen niet hestond) zou gelopen hebben, zou de uitwijking van ae bevolking van den rechter- nat den linkeroever roor gevolg hebben gehad. Die legende werd zelfs overgenomen door 2. GILLIOITS-VAN SEVEREN in zijn coutumes de la ville et du port de Nieuport, Introduction, p. 1. We vinden ze ook in A. MEYNNE: Histoire de la ville de Vieuport. Bruges, 1876 , pp. 5 en 11, in R. DUMON : Lombardsijde, in Biekorf, 45 ste jaar (1939), p. 153, en in K. LOPPENS : De yden der Vlaamsche kust. Hun ontstaan en verdwijnen, in Biekorf, 44ste jaar (1938), 1.) 290 . 
ze van het Zandhoofd 39 . Eenmaal de agglomeratie gevormd, noemden ze deze gewoonweg de «nieuwe stad. 》, of beter zoals dit toen luidde, de «nieuwe poort»: «novus portus», term, die van 1183 af voorgoed ingang vond ${ }^{40}$. De benaming «Nieuwpoort» is dan ook, evenals het statuut en het regelmatig plan van de stad, een gevolg van de oprichting van's graven domein.

\section{II. - UITBREIDING VAN 'S GRAVEN DOMEIN TE NIEUWPOORT EN OMGEVING}

Na den dood van Filips van den Elzas (1191), kwam de nieuwe stad onder het gezag van de echtgenote van den overleden graaf, Mathilde van Portugal, die er tot aan het einde van haar leven (1218) het genot van de grafelijke inkomsten bleef behouden ${ }^{1}$. "Koningin Mathilde», zoals deze vorstin zich noemde, blijkt te Nieuwpoori en omgeving enkelen van haar «milites» of vazallen met gocderen beleend te hebben, aldus «Balduinus de Novo Portu», vermeld in stukken van 1199 en $1214^{\circ}$. Ver weg het grootste gedeelte van de Nieuwpoortse ingezetenen bestond nochtans uit kleine eigenaars, die voor hun perceeltje gronds aan den vorst 's gravenlandschuld te betaien hadden. Deze bevolking was bovendien aan de parochiale geestelijkheid en aan de Sint-Niklaasabdij te Veurne de storting van het haringtiend verschuldigd. Toen in 1235

(39) « Burgenses de Sandeshovetha ». Oorkonde van 1168. L. (iILLIODTS-VAN SEVFREN : coutumes te... Nieuport, op eit, p. 151 , no IV. - « Apud novam villam de Zandhovedam ». Oorkonde van 1176. I. GILLIONTS-TAN SEVERTN : coutumes an lat rille et chatetletie de Funes, t. III, p. 23, no IV.

(40) « Ecclesiam de Novo Burgo 》. Tekst ran 1171. Chronica of (art. abb). Sancti Nic. Furnensi (Ed. F. TAN IDE PT'TES et C. L. ¿ARTON). Op cit.. p. $68 .-\ll A$ piscatoribus... Noviburqi $»$. Oor konde van 1183. L GILLIOTIS-TAN SEVEREN : Coutumes de... Tienport, op. rit., 1). 154, no VII.

(1) T. IRRS : Blavotins et Inghertins. Ins guerte mirée dans lo Flandre maritime au 12e siècle, in Bull. de la soc. dhist. de Gand. 1te année (1906), p. 177.

(2) R. DEGRYSE : Bonderign ran Tientpoort, in Bieliorf, 44ste јана (1938), р. 297-298. 
de Sinte Walburgakerk van Veurne op haar beurt op deze heffing aanspraak wilde maken, braken er te Nieuwpoort bloedige relletjes uit, tijdens dewelke twee priesters gedood en een klerk zwaar gewond werden. De ganse gemeente werd hiervoor het jaar nadien veroordeeld tot de betaling van een hele reeks boeten, renten en missen, evenals de bekostiring en de oprichting aan den rand van de staa van een grafelijke dwingburcht voorzien van grachten ". Deze vesting werd wel is waar reeds in 1242 door gravin Johanna buiten gebruik gesteld ${ }^{4}$, maar de «mote» of hoogte waarop men ze gebouwd had, bleef grafelijk domein. Ze werd in den volksmond «burg» genoemd 5 .

De landwinning in de omgeving van Nieuwpoort blijkt na de stichting van de stad niet alleen voortgezet te zijn geworden, maar bovendien de uitbreiding van de stedelijke agglomeratie in de hand te hebben gewerkt. De abdijen van den Duinen en van Burburg polderden geleidelijk de schorren in, die nabij de grote sluis en stroomopwaarts tot stand gekomen waren ${ }^{6}$. Beide abdijen lieten

(3) «...facient fortalitian Iominæe Comitissæ ae mille libris in villa de Novoportu, ut a talibus factis de ex ero arceantur; vel si lonina comitissa maluerit eam facere fleri, dabunt illi mille libras ponendas ihidem, ef insuper facient illi de rilla propis corporibus fossata quax pertinuerint ad fortalitian antedictam. 》 PAUWEL HEINDERICX : Jaerboeken wan Veurne en Teurnambacht. Deel $I$, r. 236, hijlage IV. stuk ran 13 sepiember $12: 6$.

(4) « Nos Thomas comes et Johanna uxor nostra... notum facimis... quod scabinos et communitatem de Novoportu quitavimus et absolvimus de omni eo quod nobis fuera: adjudicatum in arbitrio, qui erat inter, ipsos ex un parte ef capitnlum Beate Walburgis Furnensis ex altera, videlicet de morte presbiterorum. 》 Arch. dép. du Nord te Rijsel, no B. $1.373(729)$. Kojpie van een verdwenen oorkonde. Zie bijlage no $I$.

(5) R. DEGRYSE : Boudewijn ran Niemwport, in Biekorf, 4tste jatar (1938), p. 297 .

(6) « Item, ad orientem ville que cicitur Nieuwport, mansuram in qua domus de Dunis sita est cum appendicis suis ef riginti quatuov mensuris terre. $\gg$. VAN DE PUTTE : Cronica et cartularium mo ursterii de Dunis, op. cit., t. I, p. 200 (XCIV). Bekrachtigingsoorkonde ran December 1246 . - De abdij van isuburg verkreeg op 7 September 1244 ran gravin Johanna toelating de schorren, die in den IJzer buiten den Rietdyck in wording waren, in te dijken. L. GILLIODTSVAN SEVEREN : Coutmmes de la wille et chatellerie de Furnes, t. II, 1) 54 . Ontleding van het stuk met de autieve rermeläing «Fresdick» in plaats ran «Rietdick». Die term liomt roor in C. L. CARTON : cronica abbatum monasterii de munis, par Ad. DE BUDT. Rrugis 1839, p. 122 . 
er zich in het bezit stellen van een «utdic» of in te dijken «hemmekin» 7 . Dit gebeurde kort nadat gravin Margaretha in 1265 de «magna sclusa 》 van sassen had doen voorzien ${ }^{8}$. In de nabijheid van de sassluis ontstond terzelfder tijd een nieuwe wijk van de stad Nieuwpoort, wat aanleicing gaf onstreeks 1290 tot de stichting van een tweede kerkelijke parochie, waarvan de kerk aan Sint Laurentius toegewijd werd ${ }^{9}$. Toen gold nog steeds voor

(7) Oorkonde van Februari 1272 ten roordele van de abdij van Burburg. L. GILLIODTS-VAN SEVEREN : Coutumes de... Nieuport. Op. cit., 1. 162, no XIV. - Oorkonde van 12 Mei 1275 (naar een vidimus ran 15 Juli 1275 ) ten roordele van de abdij ran de Duinen. F. VAN DE PUTTE : Cronica et cartularium monasierii de Dunis. Op. (it., p. 162 vo (no CCCXVI). Regeling van het geschil tussen de abciij van Burburg en de abdij van de Duinen betrefferde de toekenning van de "utdiic monachorum ». Zie nopens de bijlegging van dat geschil ook C. L. CARTON : Cronica abbatum monasterii de Dunis, par Ad. DE BUDT. Brugis, 1839, p. 122, sub anno 1275.

(8) I. I. A. DIEGERICK : Inventaire des archives de la ville dPY yres, t. I, p. 89, no CIV, Ontleding van een oorkonhe van 1265 : « Lettres par lesquelles Marquerite, contesse de Flandre et de Hainaut, décice que des améliorations seront apportées aux écluses de. Nieuport et que le canal a Knocke jusqu'a l'overdragt d'Ypres sera approfondi et élargi $\%$. - De vernieuwing ran ä sluis gaf aanleiding tot een conflict tussen de watergraven van Veurne-Ambacht on de abdij ter Duinen nopens de bervaking van de verse deur, de nieuw sluisdeur. De vorstin besliste in 1269 dat de Duinenabdij ook over de sleutel van de nieuwe deur de zorg hebben zou, mar dat de door. den abt aangestelden sluismeester onder het toezicht zou staan van de Veurnse watergraven, a an wie hij bij zijn in dienst treden een eed moest afleggen. Aan cien sluismeester werd de verplichting ongelegd de rerse dem te openen, tellienmale als de watergraven dit van hem vereisten en rekenschap te geven over liet gebruik van de gelden aan hem uithetarld door de schepen, die door de sluis passeerden. F. VAN DE PUTTE : Cinica et cartmlarium monasterii de Dunis. Op. cit., p. 357, no CCLXVIII. Oorkonde van April 1269. Deze heslissing werd door vidimus van 16 Februari 1309 bekrachtigd. Ibidem, ю. 431. Zie ook p. 929 .

(9) In 1292 schonken de schepenen van Nieuwpoort een eeuwigdurende rente ran $19 \mathrm{lb}$. aan de nieuwe parochiale kerk : « Noveritis quod nos capellaniam unam in honore beati Laurentii perpetuo deservendam infra ecclesiam beati Laurentii de novo in dicta villa Noviportus fundatum pro animabus nostris predecessorum et suscessorum nostrorum, et specialiter Petri dicti Tollenace, defuncti eiusque parentum, fundavimus... ». Oorkonde $\operatorname{van}$ Mei 1292. L. GILLIODTsVAN SEVEREN : Coutumes de... Niemport. Op cit., p. 173, no XXIV. - Twee jaar roordien ontving de Laurentiuskerk van Gwijde van Dampierre een zekere oppervalite gronds, gelegen in het « porteland» tot aanlegging van een keskhof. Rijsel. Arch. dép. du Nord, B. 1375 (568). Kopie van een rerdwenen oorkonde van 18 December 1290. Op den rug van het stuk staat volgende nota : «Item copie des lettres de Guy, conte de Flandre, qui amortist une mesure de terre la ou li moustiers Saint Leurens en la ville de Nieuport siet et se $y$ donne 12 mesures de terre ». Zie bijlage no III. 
de inbezitnewing van den bodem dezelfde voorwaarden als in 1163 , namelijk de betaling van een grondcijns van $1 \mathrm{~d}$. de roede. Uit een document van dien tijd blijkt bovendien dat de ter beschikking gestelde percelen ieder een oppervlakte van 24 roeden hadden ${ }^{10}$.

De voortdurende landwinning en kolonišatie leidde ook tot de uitbreiding van het vorstelijk domein stroomafwaarts van Nieuwpoort. Aan den linkeroever van de IJzermonding, ten oosten van Oostduinkerke, ontstond onder invloed van de vooruitschrijdende zandverstuiving een nieuwe duinenketen, die de richting van de huidige kustlinie volgde. De driehoekige ruimte, die zich tot aan het Zandhoofd uitstrekte slibde aan en vormde slechts nog een «Vloedgat» of «ijde», waar de Oostduinkerkse vissers hun bootjes konden laten stranden. In de duinen zelf kwam een klein vissersgehucht, de Nieuwe IJde genoemd, tot stand ${ }^{11}$. Dit had waarschijnlijk voor gevolg dat de parochiale geestelijkheid van Oostduinkerke en Nieuwpoort elkaar de zielzorg over die nederzetting wilden betwisten. Wat er ook van zij, het bisdom Terwaan deed in 1240 door een scheidsrechterlijke commissie de grenzen van de beide parochiën afbakenen en wel op zulk een

(10) «Item sires, il vous monstrent de un autre point, ou il eut de anchienete bien use, qu'il peusent prendre et ont pris les terres cu singneur geisans en le banliewe de Nuefport pour le pourfit du commun pour le droet du singneur, c'est le maisure pour deus solz laen et en le mesure de terre en a douse et demie, c est le mesure vint et cine sol\%. "Brief waarin de lieden van Nifuwpoort hun grieven in zake het grafelijk domein in hun stad uiteenzetten. - Rijksarchief te Brussel. Trésorerie des Chartes de Flandre, no 867 . Dorument wan omstreeks 1295. Zie bijlage $n^{\circ} \mathrm{IT}$.

(11) Volgens F. VLIETINCK betekent ijde vlak strand : «een soort aanlegplaats of, zoo men wil, een schuilhaven van tweeden of derden rang, het woord schuilhaven in den breedsten zin begrepen wordende, toegepast op plaatsen waar de vartuigen der haringvisschers gemakkelijk landen en afvaren konden, zonder behuly cener genl. 》E. TLIETINCK : T'it de voorgeschiedenis onzer kuststreek. De yden van Vlaanderen, ran Duinkerle tot sluis. Geschied-en taalkundige studie. Kath. Vi. Hoogeschooluitbr., jaargang XXXV (1936), no 10 , verhandeling no 347 . - Volgens $K$. Loppens integendeel betekent ijde schuilhaven tussen de duinen, hetgeen zeker wel vail de Nieuwe IJde en Lombardie kan gezegd worden. K. LOPPENS : De ijden der Vlaamsche kust. Hun ontstan en verdwijnen, in Biekorf, 44ste jaar (1938), 1. 291-292, 


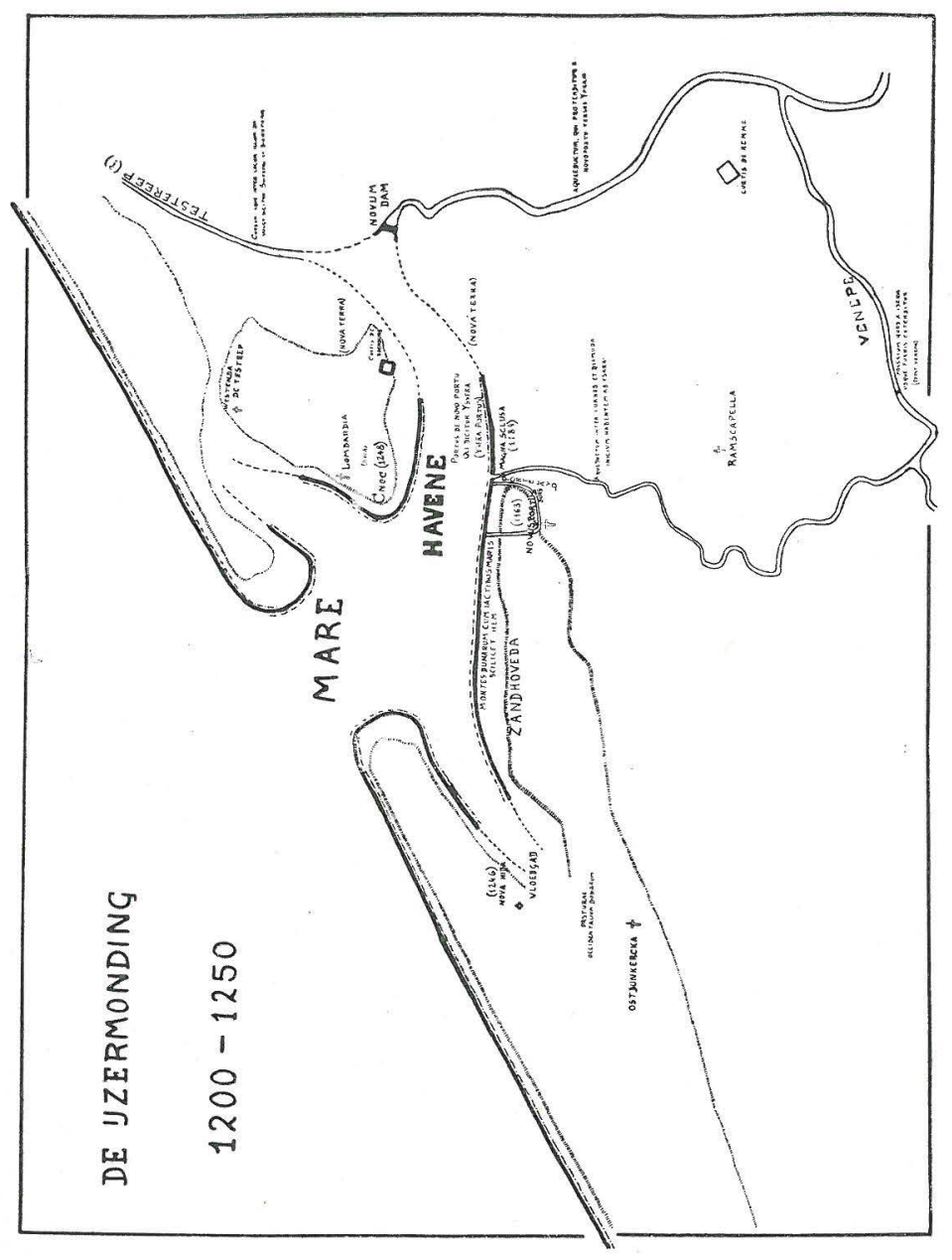


wijze dat het nieuwe gehucht bij zijn oorspronkelijke parochie bleef ${ }^{12}$. In 1246 evenwel gaf gravin Margaretha aan den baljuw van Veurne opdracht nabij het Vloedgat over te gaan tot de verkaveling van den grond en de toekenning van percelen aan degenen, die er zich blijvend wilden vestigen. In afwachting dat haar bevolking talrijk genoeg zou worden om zelf een gemeente te vormen, werd de nederzetting bij het domein en het schependom van Nieuwpoort ingelijfd en in het genot van het statuut van die stad gesteld ${ }^{13}$. De geregelde heffing van het haring-

(12) « ...debent Jimitari parrochie supradicte (oostauinkerke en Nieuwpoort) rersus aquilonem usque in mare per quoddam fossstum quod dividit pasturas occidentalium dunarum a pasiuris dunarum ballivie Nori portus. Ita quod predicti montes conarum cum iactibus maris, scilicet Hem, et alliis iactibus, et ea que sunt ad aquilonem predicte vie, ad parrochiam pertinent Novi portus ». Grensafbakening ran de parochiēn Oostruinkerke en Nieuwpoort. Oorkonde van Febmari 1240. I. GILITODTS-YAN SEVEREN : Coutumes de la ville et du port de Vieuport, p. 155, no VIII. - " Pikentores allecium de Nova Hida pertinentes ad ecclesiam de Oostduinkerke ». Oolkonde van 7 Januari 1277. F. VAN DE PUTTE: et C L. CARTON : Chronicon et cartularim abbatike s. Nicolai Furnensis. Op. eit., j. 185.

(13) « Toverint universi, quod nos Rainerum, ballivum nostrum Fuernensem, ponimus loco nostri et ei camus potestatem conferendi ex parte nostra secundum quod viderit expedire in longum et in latum fundes seu mansuras in locn, qui dicitur Vloedgad, juxta mare, sito in parrochia de Ostduinkercka, omnibus ibidem manere rolentibus. Quos omnes in dicto loco manentes et mansuros pertinere volumus arl legem, scabinagium et libertatem villw nostrw de Novoportu. Ita quod ipsi de ommihus ad scrabinagium pertinentibus justificentur ner scabinos nostros de Noroportu : hoc salvo quod multitudo populi ibidem venientis et manentis, superexcrescerit in tantum, quod per se indigeant scabinagio, eos separare possumus, si volumus, ab illis de Novoportu, et in dicto loco de Vloedgad. ipsisi per se scahinagium appropriare ad legem, consuetudinem et libertatem villa: Noviportus pradicta. De annuo rero censu dictorum fundorum aut mansurarum ordinando et taxando credere cibemus fimeli nostro domino Balduino de Balliolo et alii rel aliis, quos cum eo per litteras nostras patentes ibidem propter loc duximus trausmittendos... ». I. GILLIOUTS-VAN SEVIREA : Coutumes de Nieuport. Op cit., p. 157. no IX. Oorkonde van 6 Ang. 1246.

- Voor de vereenzelviging ran liet Vloedgat met de Nieuwe IJde, zie een telist van 1537 : « de roonomde plaetse ghenaempt de row ofte Vloetgat », « dat de zelve plaetse ran Yole es ene plaetse thelegen in een myle of daer amtrent buiten der stede ende jurisdictie van der Nieupoort up cen zeecand en binnen den dunnen ende contigue den lande van Veurnamboeht ». I. GILLIODTS-YAN SEVERFA. Ibidem, p. 262, no LVII. Oorkonde $\operatorname{ran} 1537$. - Zie betreffende de geschiedenis van het dorpje: J. VANNGRCS et le baron DE LOE : "Nieuwe Yale, un village disjurlu de la côte flumande, in Bull. de la soc. d'Anthropologie de Bruxelles, t. 37 (1922); 1923 (t. 38, pp. 182 à 203); janrgang 1924 ( $t, 39.91), 340$ à 349$)$. 
tiend werd er in 1277 ingevoerd ${ }^{14}$, wat wijst op de definitieve vestiging van de bevolking. Gwijde van Dampierre was er overigens begonnen met de inpoldering van de schorren. In 1280 schonk hij dit nog onvolledig ingedijkte gebied aan zijn zoon Guion 15, die het op zijn beurt aan zijn ouderen broeder Jan, graaf van Namen, en aan Zeger van Belle, inaarschailk van Vlaanderen, afstond ${ }^{16}$. Deze voltooiden de inpoldering en bouwden den eersten dijk, aan wiens uiteinde door toedoen van de gemeente Nieuwpoort omstreeks 1300 twee vuurbakens opgericht werden ${ }^{17}$. Dit doet vermoeden dat de ijde van Oostduinker-

(14) F. VAN DE PUTTE et C. L. CARTON : Chronicon et cartularium abtatial $\mathrm{S}$. Nicolai Furnensis. Op. cit., 1). 185. Oorkonde ran 7 Januari 1276 (oude stijl).

(15) « Nous Guis, cuens de Flandres et marchis de Namur, faisons savoir a tous ke nous domons et avons donneit, ottroions et avons ottroiet a nostre chier et ameit fil Guion le get de mer tout entierement gisant entre nostre rile de Nuefport et une autre nostre vilete kon claime le Neuveheide, et tout ce ke escheir puet ou porra de get de mer entre les derant dites riles. tout ensi comme li derant dit ges sestent dusques en le mer, et amont vers terre dusques a nos cumes, lequel get rous avons fait nouvelement en partie dikier. Lequel get devantdit nostre chiers fius Guis devantris tenra de nous et de nos hoirs seigneurs de Flandres, perpetuelment et hieretaulment, pour quatre deniers de nostre monoie de Flandres de cens par an a pailer a nostre renenghe, a le feste Saint Jehan Baptiste, chascun an perpetuelment $»$. Oorkonde ran 10 september 1280. I. GILLIODTS VAN SEVERAN : Coutumes de la rille et du poit de Nienport. Op. cit., p. 166, no XVIII.

(16) Hoe beiden in het bezit ran die polders gekomen zijn is niet zeer duidelijk. Dat het hun eigentom geworden was blijkt evenwel genoegzaam uit de oorkonde van 1306, wardoor Jan van Namen zijn polder aan de stad Nieuwport verkoopt. L. GILLIODTS-VAN SEVEREN : Coutumes de... Nieuport. Op. cit., p. 177, no XXYII. Oorkonde rin 28 Januali 1306 (en niet 1311, zoals foutief door L. Gilliodts aangegeven worcit). - Uit de grafelijke rolrekeningen blijkt dat Zeger ran Belle roor het bezit van zijn schorren en duinen aan het rorstelijk domein te Nienwpoort jaarlijks 23 1b. 18 s. betaalde, rente, die heel warschijnlijk naar de oppervlakte in gemeten berekend was. Die rente werd in 1301, of nog rroeger, door Jan ran Belle, die blijkbaar den polder ran zijn rader weêrfd had. niet meer uitbetaald. D, pachter ran den grafelijlien tol te Nieuwpoort trok indercuad ran 1301 tot 1315 ieder jaar dit bedrag af ran de door hem te betalen pachtsom : « ...de ce (pachtsom 580 lb.) rabat on pour le pasturage de le poulre qui fut monseigneur Sohier de Baillueil 23 lb. 18 s. » Rijksarchier te Brussel. Inventaire Nélis. Comtes en rouleaux, no 267. Comptes des briefs, cens, espier's et rentes. Compte de la rectte des gros de Flandre. Rekening van 1301. — " ...De cou rabat on pour le polre monsigneur Jehan de Baillœul 23 lb. 18 s. 》 Rekening van 1306. Rijksarchief te Brussel. Zelfde fond no 270 . - « Rabattu pour le polre monseigneur. Jehan de Baillœul 23 lb. 17 s. 》 Rekening ran 1315. Ibidem, no 273.

(17) Wanneer de beide « vierboeten » opgericht werden, kan niet met zekerheid gezegd worden. Een « Jan de Vierboetere » wordt in 
ke, het voormalig Vloedgat, die op deze plaats haar uitmonding moet hebben gehad, op dat ogenblik reeds in volle verzanding verkeerde ${ }^{18}$. De stad Nieuwpoort werd overigens gedwongen tot een aanhoudend toezicht over de schorren, die in de IJzermonding in wording waren en de havengeul dreigden onbruikbaar te maken. In 1307 stelde ze zich door aankoop in het bezit van den Jan Van $\mathrm{Na-}$ menpolder, die aan den westrand van de stedelijke agglomenatie grensde en een oppervlakte van $381 / 2$ gemeten 59 roeden of nagenoeg 19 hektaren besloeg. Ze betaalde daartoe aan den graaf van Namen 977 lb. 8 s. 4 d., hetzij $25 \mathrm{lb}$. het gemet, en ging de verplichting aan jaarlijks een cijns van $4 \mathrm{~d}$. het gemet aan den vorst en diens erfgenamen uit te keren ${ }^{19}$. In feite makkte voortaan ook de Jan van Namenpolder deel uit van het grafelijk domein te

1302 vermeld in de rekening ran de keukenuitgaven van Willem van Gulik. V. FRIS : De slag bij Kortrijk. Gent, 1902, p. 223. Van een «Hannin de Vierboetere » is er spraak in 1313. R. de BEAUCOUR'T de NoOR'TVELDE : Nieuport. Documents historiques, p. 130. - Van die vierbreten relf wordt roor het eerst gewag gemakkt in 1306 : « ...et d audebout du dyc vers les vierboetes ». Zie hieronder nota 19. Dat er twee vierboeten waren, blijkt uit de stadsrekeningen, die opklimmen to: 1388 .

(18) « Item lour 13 mesures et 3 quartier's de terre perdues entre Noeport et Lombardie et pour les pasturages que les dunes ont tolues cest an 6 lb. 6 s. 》 Rijksarchief te Brussel. Contes des briefs..., des gros de Flandre, no 267 (30 verso). Rekening van 's graven inkomsten ran 1301. Dit verlies werd in rekening gebracht coor Jaquemon de Diepe, den pachter ran de eijnzen « dou pasturage de le Neue Hede », die terzelfder tijd ook den tol van Nieuwpoort in pacht genomen had. Zie de topografische kaart van Belgie ol schaal 1/20.000, nitgegeven door het militair cartografisch instituut te Brussel. Blad Nieuwpoort $(12 / 5), 1934$.

(19) « Nous Jehan de Flandires, cuens de Namur, faisons scaroir a tous ceulx qui ces presentes lettres rerirront et oyrront, que nous avons a nos bons amis les eschevins, bourgmaistres. consaulx et a toute la communeaulte cie la ville de Neufpoort vendu bien et lealement, ugne poulre que nous arions gisant entre la havene de ladite rille de Neufport devers le west, et le poulre monseigneur Jehan de Baillioel, lequel poulre contient trents et huit mesures en demy mesure et cincquante neufs verges pen plus ou mains, chascune mesure pour 25 livres monnoie coursaule en Flandies, dont la somme des deniers monte 977 livres $8 \mathrm{~s}$. et 4 d., lesquels deniers $1 \mathrm{lz}$ nous ont bien et plainement parpayes en bonne monnoie coursaule, et les acquitons et clamons tout quite de la dite somme des deniers dessusdits... ». Zie voor de begrenzing van den polder den gedrukten tekst: L. GILLIODTS-VAN SEVEREN : Coutumes de la ville et du port de Nieuport, op. cit., p. 177, no XXVII. Stuk van 28 Januari 1306 (oude stijl), en niet 1311, zoals door L. GILLIODTS rerkeerd worct angegeren. 
Nieuwpoort ${ }^{20}$. Dit liet trouwens de Nieuwpoortenaars toe, door inpoldering van hun eigen schorren, hun haven te voorzien van kaaien en van een havendijk, den «dam», die in 1313 voor het eerst vermeld wordt 21 .

Twee jaar na de stichting van de Nieuwe IJde waagde gravin Margaretha een soortgelijke proef aan den rechteroever van de IJzermonding. Ook daar was de aangroei van de duinen en de aanslibbing van dien aard dat tot inpoldering kon overgegaan worden. Dit was het werk van de abdij Sint Pieter te Oudenburg, die in 1173 het bezit had verworven van al de schorren stroomafwaarts van Nieuwendamme ${ }^{22}$, omstreeks 1200 , als eerste vrucht van landwinning, haar hoeve «Bamburg» had opgericht en in 1241 eigenaarster werd van al de duinen en weiden ten zuiden van Westende ${ }^{23}$. Dit toont genoegzaam aan

(20) « Myns here Jehans polr van Amen ». Kacastraal register van is gravenlandschuld van 1313. R. de BEAUCOURT de NOORTVELDE : Tienport. Documents historiques, op. cit., p. 152.

(21) Kadastraal register van 's gravenlandschuld van 1313. Park 27 : «Item Christiaen fs. Gielis toten hoeke tsieghen den dam oestward streckende 32 d. »-- Park 28 : «Woutre Hategoed oup den nortwesthoec ran Sinte Marien strate ran den damme zuutward $\tau$ t ende drie poit. » - Item daer lighet toten damme 8 d. lants onjeloet. »Park 35 : « Christiaen en Nesekin van den Wiele 15 d. of northalf den duersstraetkine tsieghen Pieter Iaes dam. 》- "Jehan Wardin toten hoeke tsieghen den dam oestward. » R. de BEAUCOURT de NoORTVELDF: Nieuport. Documents historique, pp. 133, 134, 141. - « Du banc appelle le caye sur le harene contenant cing lines et cinquante verges de terre. D une place ou I on fait des neifz appelles scipwerkers place contenant demi mesure et quinze rerges de terre. ceulz de la ville dient que ladite kaye et la place de scipwerkers ont par éulx ste faus et gangnez sur la mer a leurs tres grans despens et que laditte kaye sert autant a monsieur que a la ville... » Rekening van is gravenlandschuld ran de jaren 1440-50. Rijksarchief te Brussel. ('hambre des comptes no 47.581 , fo 69 .

(22) Gift van Filips van den Elzas. E. FEYs et D. VAN DE CASTEELE : Histoire doudenbourg. Bruges, 1873-76, t. II, p. 97. Tekst ran cic oorkonde van 1173. - Voor de begrenzing « stroomafwarts van Xieuwendamme 》 zie een oorkonde van 18 Yei 1320. $\mathrm{T}$. de Limburg-STIRUM : La cour des comtes de flandre. I. I.e chambellan de Flandre. Gand, 1868, P. J. no LIV.

$(23)$ «...abbati et convontum de Audenburgh concessimus of denavimus perpetuo sub annuo censa duorum solidorum ac maiora brevia Brugis solvendorum in puram elemosinam ad opus pecorum necnon omnium bestiarum suarum omnem pasturam dunarum nostrarum de Westenda, siont se extendunt in longum et in latum, a curte de Boemburg usque ad viam que procedit a parte maris septemtrionalis rersus ecclesiam de Westende inter altas dunas et dicum qui jacet contra domum Weinin sitam iuxta eandem ecclesiam versus orientem. 》 E. VEYS et D. VAN DE CASTEELE : Histoire d'Oudenbourg, op. cit, p. 100: Oorkonde ran December 1241. 
hoe het duinencomplex aldaar veld won. Ook daar bleef een «ijde» open, waar de vissers van Westende hun bootjes konden laten stranden ${ }^{2 t}$ en ontstond er in de nabijheid een klein gehucht. Dit werd gebouwd op de plaats genoemd "Cnoc», een van de hoogste duinen " dra genoemd naar een zekeren Lombard - wellicht iemand uit de streek 26 - «Lombardie» en niet Lombardsijde ${ }^{27}$. In 1249 gelastie Margaretha van Constantinopel de baljuw van Veurne met de toekenning te Cnoc van percelen gronds aan degenen, die er zich voorgoed wilden nederzetten. Krachtens zijn stichtingsoorkonde werd Lombardsijde onmiddellijk tot den rang van gemeente verheven en in het genot van het statuut van Nieuwpoort gesteld ${ }^{-8}$. Zijn kerkelijke parochie wordt reeds in 1263 vermeld 29 . De eigenlijke stichtingsoperatie blijkt noch-

(24) De kieek van Lompardsijde bestaat nog steeds op onze dagen. Zie de militaire stafkart ran Belgiē, op schaal $1 / 20.000$, blad Nieuw poort $(12 / 5)$. Orer die kreek zie K. LOPPENS : De ijden der Vlaamsche kust. Hun ontstan en verdwijnen, in Biekorf. 44ste jaar (1938), 1). 290

(25) « Knok» betekent hoogte. De term komt orereen met « altas dunas 》 in het stuk van 12t1, nota 23 hierboven.

(26) Ine familienaam Lombard treft men kort na de oprichting van gemeente te Lombardsijde aan. In 1313 worcit inderdaad gewag gemaakt ran ten "Clais Lombard, de coster 》, in het register ran 's graventandschuld ran dat jaar. R. de BEAUCOURT de NOORTreuDe : Nieuport. Documents historiques, t. II, D. 111. - Zie ook li. DEGirise : Stichting van Iombardsijale, in Biekorf, 46ste jaar $(19+0), 1) .92$.

(2T) De term Lombardie is tot kort na 1400 de enige gebruikte naam roor Lombardsijde. Zie Edw. VLIFTINCK : De IJden van Vlansteren, op. cit., p. 11.

(28) « Noverint universi quod nos Christianum, balluvum nostrum Furnensem, ponimus loco nostri pro mansuris dandis et assignandis in loco qui dicitur cnoc contra Novum Portum versus Orientem. Concedentes illis qui in dicto loco ad manendum renire voluerint, quod habeant eandem libertatem, legem et scabinagium quod habent illi de Novo Portu ». Oorkonce van 27 Februal'i 1248 (oude stijl). L. GILLIODTS-VAN SEVEREN : Coutumes de la ville et chatellenie de Furnes, t. IV. Coutumes de Lombardside, Loo et Poperinghe, p. 13, no 1.

- De rereenzelviging van Cnoe nie Lordbardsijde is betwist geworden. Zie hierover K. LOPPENS : Het dorp Cnoc bij Niemopoort, in Biekorf, 43ste jaar (1937), bladz. 9. De stichtingsoorkonde draagt nochtans op haar rug den titel « litteria communitatis de Lombardie 》, wat alle twijfel uitsluit.

(29) «In dicta parrochia de Westenda, prout se antiquus extenabat antequam parrochia Lombardie fieret $»$. Rijksarchief te Brugge. Abbaye d'oudenbourg, no $795 \mathrm{t}$ (101), no bleu 6738. Oorkonde ran April 1263. 
tans een twintigtal jaren in beslag te hebben genomen. Al te zamen werden zowat 61 gemeten gronds, die aan de abdij van Oudenburg toebehoorden, onteigend en verkaveld ${ }^{30}$. Eerst in 1269 vaardigde gravin Margaretha een keure uit, die de juridische verhouding van Lombardsijde ten opzichte van Nieuwpoort, alsmede het fiskaal statuut van het nieuw stadje definitief regelde 31 . Door deze regeling werd Nieuwpoort het wettig hoofd van Lombardsijde 32 en bleef de IJzerrede in haar geheel Nieuwpoorts rechtsgebied ${ }^{33}$. De lieden van Lombardsijde mochten er slechts kopen en verkopen binnen den grafelijken tolboom. Uitzondering werd alleen gemaakt voor de kleine hoeveelheden vis, die ze voor eigen gebruik uit zee aanvoerden 34. Voortaan werden's gravenlandschuld, de

(30) « Nons, Margherite contesse de Flandres et de Haynau faisons a savoir a tous, ke comme nos eussiens iadis faite et estoree nostre vile de Lombardie daleis notre port de Noefport et ke nous a ceans de celi vile te Lombardie cussiens dounei masures partie es dunes u il ont maisonnei, et partie seur le hem rers Noefport, dont nous avons ades puis receues et recerons les rentes. Et comme li abes et li couvens de Audembourg se plainsissent devant nous souvent, ke nous rele vile ariens estoree et les.masures dounees tout seur le leur, ، est a savol on partie sul lor pasture, qu il ont es dunes dou don de nous ancissenrs et en partie seur le hem ki est lor iretages par le don de nos ancisseurs ausi. si comme il apeirt par lor chartes, nous (nvoiames religieus home... pour enquerre de ces choses au lin devant dit. Et nos raporterent... ke dehor's le liu u li vile est maisonee, nos gens aroient dounei a ceaus de Lombardie pour masures seur le pasture de ceaus do Audembourg treinte et cuinc mesures, domse verges mains, es ruts sis mesures, deus lignes et trente verghes, et seur le hem, ki hiritages est de l'Eglise de Audembourg, quinze mesures, ciunquante verges et in lues quatre mesures, et ke de ce nous avous reciut et recevons les rentes. "Oorkonde van 16 Oktober 1274 , naar een videmus vilu $t$ Norember 1293. Rijksarchief te Gent. Fonds de Saint-Genois, no 184 . Zie hieronder bijlage no II.

- De oppervlakte door de gravin aangeslagen en aan Lombardsijde weven bedroeg dus al te zamen 60 gemeten, 2 lijnen en 92 roeden. Hiervan waren 50 gemeten en 62 roeden bestemd voor cijnsgoederen, roor lewelke de bewoners renten ('s gravenlandschuld) te betalen hadiden, terwijl de rest, 10 gemeten, 2 lijnen en 30 roeden, bezet werd door de straten, voor develke geen cijnzen gestort moesten worden.

(31) Appointement ran gravin Margaretha van April 1269. I. GILLAODTS-VAN SFVGREN : Coutumes de la ville et chatellenie de furnes. t. IV. Coutumes de Lombardside, Loo et Poperinghe, p. 14, no 11.

(32) « Ke cil de Noffport doivent estre chief de ceaus de Iombardie pt doivent estre desous le baillin de Furnes ». Tbidem, art. 1 .

(33) « Et si coit tous li avenes demorer entirement a le ville de Noefport, tout ausi comme il 1 ont mannie et tenu iuskes au jour dui. Si ne puet on rendre ne achater, se dedens de tolneboem.... 》. Ibidem, art. 7 . 
stalpenning, de «forage 》 en de andere kleinere grafelijke rechten in de beide zustergemeenten op dezelfde wijze door den tollenaar geheven ${ }^{35}$. Reeds in 1273 evenwel wist de stad Nieuwpoori voor zichzelf en voor haar gehucht, de Nieuwe IJde, de afschaffing van de stalpenning en van het grafelijk prerogatief, dat dit recht vertegenwoordigde, te bekomen ${ }^{36}$, zodat van dit ogenblik af dit recognitiegeld alleen nog door de lieden van Lombardsijde te betalen was. Voor het overige bleef het fiskaal statuut van de twee zustersteden nagenoeg identisch.

\section{III. - BEHEER VAN'S GRAVEN DOMEIN TE NIEUWPOORT EN OMGEVING}

Van het einde van de 13 de eeuw af kunnen wij, dank zij de grafelijke rolrekeningen, het beheer van het vorstelijk domein te Nieuwpoort en omgeving in zijn grote trekken nagaan ${ }^{1}$. Dit domein, «tol van Nieuwpoort» genoemd, werd onderverdeeld in de «rentes et censes》, die door de ingezetenen van Nieuwpoort en Lombarsijde te

(34) «...cil de le vile de Lombardie pooront de ce qu il prenderont te herens es neis de la vile de Lombardie, soit a compaingnie u en lor neis propres sans achat faire lor volontei... $\gg$ Ibidem, art. 7 .

(35) « Et si coivent cil de Lombardei paier a nous et a nos hoirs singneurs de Flandres, en non de tonlieu. forage, estallaige, et autres droitures en la ville de Lombardie, comme li bourgois de Noefport ». Ibidem, art. 11

- Opvallend is het hoe de keure van 1269 ook bepaalt dat de burgers van Nieurpoort niet te Lombardsijde, evenmin als de lieden ran dit stadje te Nieuwpoort mochten gaan wonen, tenzij in geval van huwelijk of van erfenis, wat zeker in verband met 's graren fiskale politiek moet worden gebracht : « Et si ne puet nus de Noefport renir manoir a Lombardie, ne de Lombardie a Noefport, se non par mariage, u par escheance de fourmorture ». Ibidem. art. 2.

(36) « Encore rolons nous, contesse derant dite ke tout saichent ke comme il soit ensi ke nous aiens eu en la derantdite vile de Neufport, une rente ke on apiele stalpeming, lequele on nous i soloit paier cascun an, nous pour Dieu et en nom de restor et d amendement deseuredis, ladite et le droit ke nous avons en cele rente, quitons et -lamons qiute a cheaus de le dite vile de Nuefport, et volons ke il en soient quite des ore en avant perpetuelment. » Oorkonde van gravin Margaretha van Mei 1275. L GILLIODTS-VAN SEVEREN : Coutumes de... Nieupart. Op. cit., p. $166, n^{\circ} \mathrm{XVJI}$.

(1) Brussel. Rijksarchief. Chambre des comptes nrs 267, 269, 270, $271,272,273,274,277$. Grafelijke rolrekeningen van $1301,1317$. 1306, 1309, 1312, 1315, 1316 en 1321. 
betalen waren, en de 《aventures》 of tollen, die op het handelsverkeer en de handelsverrichtingen in de IJzerrede drukten ${ }^{2}$. De Nieuwpoortse tol werd aanvankelijk, onder de regering van Gwijde van Dampierre, om de drie jaar bij openbare aanbesteding aan den meestbiedende verpacht. De eigenlijke aanbesteding liep over het algemeen over een vol jaar en ging op Sint-Jansdag (24 Juni) in. Het gebeurde ook dat ze slechts over een half jaar liep, meer bepaald van Sint Jansdag tot den daaropvolgeriden Kerstdag of van Kerstdag tot den daaropvolgenden Sint-Jansdag ". Wat er ook van zij, de tollenaars dienden de door hen te betalen pachtprijs op de te heffen rechten te verhalen en dan nog wel op zulk een wijze, dat ze winst makkten. Voor de inning van 's gravenlandschuld bedienden ze zich van een door hen opgesteld kadaster bestaande uit de opsomming per «park》 van de cijnsplichtige percelen te Nieuwpoort, de Nieuwe IJde en Lombardsijde. Blijkbaar was de oppervlakte gronds waarop de cijns drukte eens voor altijd vastgesteld geworden. Dit was althans het geval voor Lombardsijde, waar de totale oppervlakte aan cijnsgronden 50 gemeten en 62 roeden of ietwat meer bedroeg ${ }^{4}$. De op-

(2) « Compte de le cense dou tonliu de Noefport fait par Jehan riande, qui le commoncha en le main mons, au noel 1 an vint sen comt. rech. sour tout pour les rentes et censes d nune annee eskeue a le Saint Jehan 1 an vint et un et pour les aventures d une demie annee eskeuwe a le di:e Saint Jehan 408 lb. 4 s. 5 d. \$ Ibiciem, no 277 , rekening van 1321 .

(3) « Contes de le cense dou tonliu de Noefport fait par Jehan dou Sac de Neufport et fina li cense a le Nativiteit Saint Jehan l an 1306 , cont li somme fu pour cest an 520 lb. 》 Ibidem, no 270. Rubriek : « Ens le baillie de Bierghes e de Furnes ». - « Compte de le cense dou tomliu de Nuefport fais par Jakemes de Cranenbourg de le Nativiteit Jaint Jehan Baptiste ! an M.CCC et wit Guskes a le Naptivite Notre segneur alurs suiwant, dont li somme est por re terme $3201 \mathrm{~b}$. feule momnoic $» .-$ “ompte Gillion de Harceberghe de le ditte chnse, lequelle il a pris a tenir de le ditte Naptivite Notre Segneur 1 an M.CCC. et wit duskes a le Naptivite Saint Jehan 1 an M.CC.C. et neuf, cest par demi an. dont li somme est pour ce terme 340 lb. bonne monnoie 》. Ibidem, no 271.

(4) « Dit is de lantscout ran Lombardie de grote der of die mijn here de grave nebbet oup che hofsteden verniewet in t jaer ons heren M.CCC: ende dartiene ts anders daghes na onser vrouwen dagh in Marte... « Ende dese vorzeide paijement ran Lombardie ghelt me te Midewintre encre te Paschen. Somme van den paijmente van mide- 
brengst van 's gravenlandschuld schijnt dan ook theoretisch uit een vast jaarlijks gedrag te hebben bestaan. We zien inderdaad in het begin van de 13 de eeuw de pachters van cien Nieuwpoortsen tol ieder jaar op de door hen te betalen pachtprijs een zekere som in mindering brengen voor de onbewoonde, ontruimde of verlaten percelen, waarvan de eigenaars den grondcijns verschuldigd gebleven waren ". Het oudste kadastraal register van 's gravenlandschuld, dat tót ons kwam en van 1313 dagtekent, bevat bovendien de lijst van de lieden van Lombardsijde, die in ruil voor tolvrijdom te Nieuwpoort, den stalpenning betaalden ${ }^{6}$.

Tot de «rentes et censes», die de burgers van Nieuwpoort en Lombarsijde aan de tollenaars te betalen hadden, behoorden ook enkele rechten op het brood, het bier, de

winter 31 lb. 8 s. ende $81 / 2$ d. par. Item somme van den paijemente van Paschen 31 lbs. 8 s. ende $81 / 2 \mathrm{lb}$. par. Somme ran desen tween sommen vorzeit $62 \mathrm{lb} .17 \mathrm{~s}$. ende $\tilde{5}$ d. 》 $R$. de BEAUCOURT de NOORTVELDE : Nieuport. Documents historiques, pp. 156, 161. Kadastraal register van is gravenlandschuld van 1313. - In 1274 werd als totale cijnsbare oppervlakte aangegeven : 50 gemeten 62 roeden. De juiste oppervlakte, die corresponcert aan $62 \mathrm{lb} .17 \mathrm{~s} .5 \mathrm{~d}$. is : 50 gemetei en 89 roeden, dus ietwat meer. Zie hierboven p..., nota 30 .

(5) «Item pour masures perdues, 28 s. 》 Rekening van 1308 . "Item en faute sour les nasures perdues, pour demi an $14 s$. » « Item pou: les masures peidues $14 \mathrm{~s}$. ». Rekening van 1309 . — « Item en deffaute sour les masures vuides $28 \mathrm{~s}$. cest an ». Rekening ran 1312. Brussel. Rijksarchief. Chambre des Comptes. Compte de la recette des gros de Flandre, no 270, 271 en 272.

(6) «Dit es de boee van den hofsteckenlande van der Nieuwerpoort dan of dat mate liep di den here wetteleike in 't jaer Ons Heren duzentich driehondert ende clartiene in de vasterne iemeten van steden te steichen bi parken, also hier naar iescreven ende ieordinert staet, jesommert oup elken man zine grote wat hi tsiaers in elk van cen parken ghelden zal daer elc mensche land in hebbet. Fnde biden brieve in $t$ ende van desen boeke jescreven ende biden jetellen me ral vinden elcs mans name in wat parke $t$ sijn licghet, begonnen ten oostende van der steide buten brughen westwaert streckende ». Brussel. Rijksarchief. Tresorerie des Chartes de Flançue, no 855, 1 recto. Uitgegeven door R. de BEAUCOURT de NOORTVELDE : Nienport. Documents historiques, p. 111-166. — « Dit zijn degheene die hare stalpenninghe ghelden te Lombardie oup sinte Brixis dach, ende die nie ne coemt oup Sinte Brixsisclach mit $4 \mathrm{~d}$. par., hie es al $t$ jaer ontvrijet van zinen porterachepe. 》 Ibidem, p. 161. - «omme $3 \mathrm{lb}$. ende 14 s. par. 》 Tbidem, p. 166. - Het behoud ran dit belangrijk dokument danken wij blijkbaar aan het feit, dat de tollenaar, die het opmaakte, Pieter van den Leene, op dat ogenblik niet een gewoon pachter, maar wel een grafelijk officier was. 
wijn en de pluimen en misschien ook op de gronden ${ }^{\top}$. De eerste van deze tollen, de broodtol, die door de bakkers aanvankelijk in natura uitgekeerd werd en per week één broodje van een obool bedroeg, moet snel in onbruik geraakt zijn, vermits hij alleen in de keure van 1163 vermeld wordt '. De wijntol of «forage», die oorspronkelijk eveneens in natura uitbetaald werd en één zester het vat bedroeg ${ }^{9}$, moet integendeel vóór $1269^{10}$ in een geldelijke heffing omgezet geworden zijn ${ }^{11}$. De tol op het brouwen

(7) Keure ran Nieuwpoort ran 1163. L. GILLIOITS-VAN SEVEREN : Coutumes de... Nieuport, pp. 144-145. Zie hierboven p. Tt, uota's 19 en 21.

(8) «Quicumque panes renales fecerit, in die sabbati, panem de obole dabit. " Keure van Nieuwpoort van 1163, art. 18. L. GILLIODTsVAN SEVEREN : Coutumes de la ville et du port de Nienport, op. cit., 1. 144 .

(9) "Quicunque vinum rendicerit more taherne, sextarium vini (labit de uno vase. 》 Ibidem, art. 20.

(10) De «forage 》 wordt in 1269 roor het eerst als geldelijke bijdrage vermeld. I. GILLIODTS-YAN SEVERWN : routumes de la ville et chatellenie de Furnes. t. IV, p. 1t, no II. - Vie hierboven p......, nota 35.

(11) « Van elken sticke wijns 4 d. ob. p. 》 ... « Item van wyn consille van de sticke + d. ub. p. 》 Toltarief van 1463 . Brussel. Rijlisarchief. Chambre des comptes, 45982. - " Dit es de usance van den toolne van des Nieuport gheuseert ende ontfanghen by Jan den Bil ende zine medepleghers in $t$ jaer 61,62 ende 63. 》 Ongernaakt in 1468 - * Ainsi print et extrait d un papier et signe de la main du dit Jehan de Bil, 1 un des fermiers, employe en certain proces le 20 jour de Septembre anno 1468. 》

-.. Mee" bijzonderheden over de heffing van de "afforage " vernemen we ter gelegenheid van een geschil, dat in 1431 tussen ch wchepenen van Lombardsijde en de Nieuwportse tollenaars uitbrak. Jeze laatsien betoogden dat : « Onder dander heerlicheden ends seignourian onsen voornomden heere toebehorende hem behoorde toe de toolne of afforage binnen zynen stede van Lombarcie in zulke voorme ende maniere als men se hadde binnen der zelver stede van der Nienwerpoort zonder eenich ondersceet of veranderinghe ende dat in de roornomde stede van der Nieuwerpoort alle daghone die tappen of wyn of bier vercoehten valn wat conditien dat $z y$ waeren, waren \%r scepenen of negheene, betalden afforage zonder eenich ondersceet of rryhede te hebbene, i een meer dan d augere of het ne ware dat speciale gracien of previlegen vall den prinche men beloghen mochte dat zy exempt waren, encic was $t$ vorseide afforage van bede dim steden een pacht diemen nam of rerpachtede jeghen den on fanghere grmerael van vlaendren ende al diare ghelyke was de tol van beede den voornomden steden een parht in zulker wys, dat zonder die te sceedene, wie con voornomden tol of afforage pachtede jeghen den zelren ontfanghere hy wasst also wel van der eenre stede als van der andere, ende als poorters ran der zelver stede van der Nieuwerpoort de roomomde afforagen respacht hadden, zy. hadden romtyds de afforagen van beecic den voorseiden steden ontfaen ende ghegadert by hem of hatren dienaers ende zomtyds $\% y$ hadden ghedaen gaderen 
en het verkopen van inheems bier en die op den verkoop van uitheems bier werden nooit afgeschaft. Alleen hun schaal werd in den loop van de tijden gewijzigd ${ }^{12}$. Hetzelfde kan gezegd worden van den tol op de pluimen, of beter op de pluimbedden en met pluimen gevulde kussens, die, alhoewel in den beginne als recognitiegeld bedoeld ${ }^{13}$, in de 15 de eeuw nog als een echte tol geheven werd 14. Over den toi op den verkoop en den aankoop van gronden hebben we echter geen nadere bijzonderheden aangetroffen.

Voor de heffing van de menigvuldige tollen op de handelsverrichtingen en het handelsverkeer bedienden de tollenaars zich van een door den graaf geformuleerd tarief. De oudste schaal van dien aard is die van 1163, opgesteld op last van Filips van den Elzas en vervat in de keure van Nieuwpoort ${ }^{15}$. Ze geeft de opsomming van de verschillende handelsartikelen waarop in de haven of op de markt, zowel bij den aankoop als bij den verkoop, en soms ook bij

de voorseide afforagen van der Nieuwerpoort ende voort verpacht eeneghe van Iombardie die te heffene in zulker manieren als mense hief ter Nieuwerpoort vorseit, zonder eenighe differencie daer tusschen te makene... \$ L. GILLIODTS-VAN SEVEREN : Coutumes de Lombardside, too et Poperinghe, op. cit.. no VII, oorkonde van 8 Juni 1431 .

(12) "Quicumque cervisiam fecerit, de una cervisia duos denarios debet. Et quicunque extraneam cervisiam vel extraneum medonem vendiderit, de rase uno denariatam unam debet. 》 Keure van Nieuwpert van 1163, art. 17. T. GILLIODTS-VAN SEVEREN : Coutumes de... Nieuport, op. cit., p. 144. — « Van elker braute biers 6 s. p. 》 - "Van twee tonne biers 4 a. ob. 》 - «Van bier aysille van den tonne 2 d. ob. "Toltailef ran 1468. Brussel. Rijksarchief. Chambre ces Comptes, no 45982 .

(13) "Concessi etiam opidanis meis de novo opido, quod quicumque ibi manserit, ab omni teloneo, nisi sit de terra vel de plumis liber erit. 》 - « Lectum vendens duos dabit denarios; emens duos. Qui emit pelu, obolum dabit, et qui rendit obolum. » Keure van Nieuwpoort van 1163, ant. 15,21 en 22 . Dat het hier werkelijk pluimenberlden en penluws gold, blijkt uit art. 24 : «Qui extraneus lectum sine plumis vendicerit, unum denarium dabit. et qui emerit unum. » L. GIILIODTS-VAN SEVEREN : Cotumes... de Nieuport, pp. 144, 145.

(14) « Nieupoort vry ran toolne zonder van land, van plumen ende van oollove... - « Van bedden of zac plumen van den stick 2 s.p. Item va nplumen die binnen der stede vercocht worden, de coopere ende de vercoopere ooc 12 a. s. Item ran cussen daer plumen in zyn van elcken hoecke, eenen penninc. $\gg$ Toltarief van 1468. Brussel. Rijksarchief. Chambre des Comptes, no 45982.

(15) L. GILLIODTS-VAN SWVERFN : Coutumes... de Nieuport, op. cit., p. 144-148. 
den uitvoer, tollen drukten ${ }^{16}$. Ze somt ook de schepen $o p$, die kaaigeld verschuldigd waren, en de schuiten en de voertuigen, waarvan bij den aan- of uitvoer van waren tollen geëist werden ${ }^{17}$. Het ligt voor de hand, dat dit tarief niet ongewijzigd gebleven is, maar in den loop van de tijden steeds aan de noodivendigheden van de tolheffing aangepast geworden is. Aldus wisten de Nieuwpoortenaars in 1241 van Johanna van Constantinopel te verkrijgen, dat de tollen, die drukten op de schuiten gebruikt voor den aanvoer van hun waren en op de wagens gebruikt voor den uitvoer van hun goederen, afgeschaft werden ${ }^{13}$. Integendeel werden vanaf de opening van het Ieperleed, dat Brugge over Nieuwpoort en den IJzer met Ieper verbond en omstreeks 1300 tot stand kwam ${ }^{19}$, tollen geheven op zekere koopwaren doorgevoerd «sonder haer last te brekene» ${ }^{20}$, wat voordien niet het geval was 21 .

(16) «Si navis intraverit, nullus inde aliquid emet, donec maris sedeat, forisfactum inde tres libras. De dacara coriorum, vendens duos denarios, emens duos denarios. It qui detulerit denarium unum... De pensa caseorum Anglicorum qui detulerit denarium unum; qui vendicrerit, duos denarios; qui emerit, dros denarios enz. 》 Keure van Nieuwpoort van 1163, art. 29. ibidem, p. 146.

(17) « De nave, que vocatur scuta, unum denarium... De nave, que est clincaboiat, duodecim denarios. De nave, que dicitur losboiat, octo denarios. De nave, que dicitur envara, quatuor denarios. De cogga, octo denarios. 》- «De plaustro abeunte quatuor denarios, et de veniente plaustro, unum denarium. De biga abeunte, duos denarios. De biga intrante obolum. 》 Ibidem, pp. 145, 147.

(18) «Preteria cum apua Novum Portum exigeantur quatuor denarii de curru et de biga deferente bona cujuscumque de quibus theloneum debitum est solutum et de scutis afferentibus bona illorum de Novoportu ibidem duo denarii exigantur. Nos intelligentes hoc esse pocius exactionem quam debitum, ipsos de dictis quatuor denariis de curru et de biga et de cuobus denariis de scutis in perpetuum quitamus et absolvimus pro nobis et successoribus nostris. 》 Oorkonde van September 1241. Rijsel. Arch. aép. du Nord, B. 1373 (729). Kopij van een verloren stuk. Zie bijlage. no II. - Vergelijk hierbij den tekst ran de keure van Nieuwpoort, nota hierboven.

(19) R. DEGRYSE : Oude en nieume Havens van het IJzerbekken, in Handelingen van het Genootschap voor Geschiedlenis "Société d'Emulation 》. Jaar 1947, deel 84, pp. 6-40 (p. 25).

(20) «Item van elken zack die men duervoert gherult met cooren d. »- "Item van elken hondert yscot cuerlydene, d. » enz. Toltarief ran 1468. Brussel. Rijksarchief. Chambre des Comptes, no 45982. Zie hieronder nota's 30 en 72 .

(21) «Quicunque res per opidum transierit. si deposita non fuerit, libera erit. 》 Keure van Nieuwpoort van 1163. I. GIIJIOITS-VAN SEVEREN : Contumes... de Nieuport. Op cit., p. 147. 
De tollenaars diencien ook rekening te houden mst de gemeenten, die te Nieuwpoort tolvrijdom bezaten. Volledigen vrijdom genoten de lieden van Nieuwpoort sedert $1163^{22}$, die van Veurne sedert $1176^{23}$, die van Duinkerke sedert 1190 ongeveer ${ }^{24}$, die van Muide sedert $1242^{25}$, die van de Nieuwe IJde sedert $1246^{\circ}{ }^{\circ}$, die van Lombardsijde sedert $1249^{27}$, die van Slus en Brugge sedert 129328 en die van Grevelinge en Mardijk sedert een ongekenden datum. Gedeeltelijken tolvrijdom genoten de burgers van Ieper ${ }^{29}$, de Noordvierschaar van VeurneAmbacht, de lieden van Sint-Omaars en van Hulst ${ }^{30}$.

De verpachting van de «tol van Nieuwpoort» bracht

(22) L. GILIIODTS-VAN SLVEREN : Coutumes de la ville ef du port de Nienport. Op eit., p. 14t. Keure van Nieuwport (1163), art. 15.

(23) L. GIIIIODTS-YAN SEVEREN : Contumes de la wille et chatellenie de Furnes, t. III, p. 23, no IV. Voorrecht valn tolvrijglom te land pn te water in de « novam villam Zandhovedan 》.

(24) Voordecht van tolvijom, wan Vhanderen door, verleend aan Inuinkerke door Filip van den Iflats. I' VAN DUYsis et E. DE BusSCHER : Incentaice analytique des chastes et documents appartenant anx archives te la ville de fiand. Ciand. 1867, 1) t. Niet gerlateerde otorkonde (1168-91).

(25) L. A. WARNKOENIt: Flandrische stats- mat rechtsgeschichte bis an Jahre 1305. Op eit., II, 2, D. 60. Voorrecht van tolvrijdom te Damme, Nienwpoort en Duinkerke. Oorkonde ran Maart 1242.

(26) Volgens do stichtingsoorkonde van Git Nicuwpoorts gehucht.

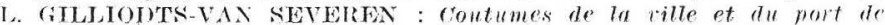
lieuport. Op cit. r. 1.5T, no IX. Stuk van 6 Augustus 1246.

(27) Krachtens de stichtingsoorkonde van dit s'adje. L. (iILLIOI)Ts VAN SEVEREN : Coutumes des lays et comté de Flandre Quaties de Furnes, t. IV : Gotumes de tomberdside, D, 13, no I. stuk vall 27 Februal'i 1248 (oude stijl).

(28). R. HAPKE: Die Entstehung von sluis, in Hansische Geschichtsbiätter, 1904-05, pp. 65-80. - A. DE SMET : lioridine des Ports du Zuin : Damme, Hude. Monikerede, Hoeke of sluis, in Etudes d'Jistoire dédices à la Hémoire de Henri Pirenne. Bruxelles. 1937.

(29) Verdwenen oorkonde van 1275. L. A. WARNKOENIG-(iItEL

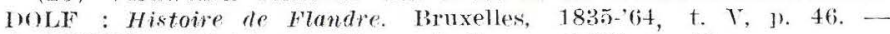
A. MEYNE : Histoive de Nieuport. Bruges, 1876,1 , 46.

(30) " J hit zym deghune, die de voornoemde Jan de Bil pnde zine modepleghers hilden vir van toonen. Eerst. Die ran Brugghe, Oostenue, sluns, Inunkerke, Mardyk, (freveninghe, Veurne metter... van sinte Wouburghen ende alle kerkalyherlen, ah omni teoloneo. Sint (Omaers. de Nontrierseare ran Vemm Ambacht, Hulst. (Gheen last breken. 》 Tit het toltarief ran 1401 - $^{-}(3)$, ongesteld door den tollenaar Jan de Sil in 1468. Brussel. Rijksarchief. C'hambre des comptes. no 45.982. - Oostende genoot tolvrijicom te Nieuwpoort eerst sedert 1419. I. GILLIODTS-VAN SEVEREN : Coutumes des petites villes... dans le Franc de Bruges, t. IV : Coutumes de la ville dostende, p. 46. Tol vrijolom gans Vlatanderen iloor. Oorkonde van 7 Jamuari 1419. 
in $1301580 \mathrm{lb}$. op, in 1306520 lb., in 1309, verdeeld over twee halfjaarlijkse termijnen, $660 \mathrm{lb}$. en in $1312680 \mathrm{lb} .{ }^{31}$. Haar opbrengst ging dus schijnbaar in stijgende lijn. In werkelijkheid gaf $z_{e}$ aanleiding tot zekere misbruiken vanwege de pachters. Zoo beklaagden de Nieuwpoortenaars omstreeks 1295 er zich over, dat de tollenaar soms tegelijk ook schepen of baljuw was en onwettige tollen hief, o.a. op het ditheems bier, en eisten daarom de instelling van drie. afzonderlijke «briefs», tespectievelijk voor elk van de drie functies ${ }^{32}$. Anderzijds nam de tollenaar de gewoonte aan op de door hem te betalen pachtsom allerlei onkosten in mindering te brengen, meer bepaald de uitgaven voor het herzien van het kadaster van 's gravenlandschuld ${ }^{33}$, de onkosten van de herstellingen aan den boot dienende bij de tolheffing in de haven ${ }^{34}$, de verliezen voortkomende van de niet vereffening van 's gravenlandschuld door de verlaten percelen 35 en dezen voortspruitende uit den tolvrijdom, die toenmaals pas aan de lieden van Sluis en Brugge verleend geworden was 36.

(31) Zie de grafelijke rolrekeningen van 1301, 1306, 1309 en 1312 . Brussel. Rijksarchief. Chambre des Comptes, nos 267, 270, 271 en 272. Zie ook hierboven nota 3.

(32) Zie bijlage IV bij dit artikel. Tekst van een klaagschrift waarin de lieden van Nieuwpoort hun grieven in zake het grafelijk domein in hun stad uitcenzetten. Stuk van omstreeks 1300. Brussel, Rijksarchief. Trésorerie cies Chartes de Flandre, no 867.

(33) « Item pour les mesures refaire cest an $100 \mathrm{~s} .(1306)$. - « Item pour les mesures refaire $100 \mathrm{~s}$. 》 (1309). - « Item pour les mesures refaire cest an 4 lb. » (1312). Rijksarchief. Chambre des Comptes. Rolrekeningen no 270, 271 en 272. Rekeningen van de jaren 1306, 1309 cn 1312 .

(34) «Item pour le batiel refaire $28 \mathrm{~s}$. (1306). - « Item pour Te batiel refaire, $c$ on refait constans en yvier 12 lb. » (1309). «Item pour le batiel refaire cest an $5 \mathrm{lb}$. 》 (1312). - « Item pour le batiel refaire cest an 40 s. » (1316). Ibidem no 270, 271, 272 en 274. Rekeningen van de jaren 1306. 1309, 1312 en 1316.

(35) «Item pour masures perdus $28 \mathrm{~s}$. 》 (1306). - « Item en faute sour les masures perdues, pour demi an 14 s. » (1309). "Item en deffaute sour les masures vuides 28 s. e'est an. " (1312). Ibidem no 270,271 en 272 . Rekeningen van de jaren 1306, 1309 eu 1312.

(36) « Item pour le toniin de cieus de 1 Esclusse, $k$ il devoient a cest tonliu de leurs marcandises $4 \mathrm{lb} .10 \mathrm{~d}$. ». Ibiciem, no 270 , rekening van 1306. - « Item pour le tonliu de chiaus de Bruges $\mathrm{k}$ il devoient de leurs marcandises a cest tonliu. » Ibidem, zelfde rekening. - " Item pour le tonliu de cheaus del Escluse effrankis $11 \mathrm{lb} .4 \mathrm{~s} .7 \mathrm{~d}$. 》 Ibidem, no 272 , rekening van 1312 . - " Et pour le tonliu ciaus del Fscluse pour cest an $10 \mathrm{lb}$. 》 Ibidem, $\mathrm{n}^{\mathrm{s}} 273$, rekening van 1315 . 
De graaf stelde dan ook in Augustus 1312 Pieter van den Leene van ambtswege als tollenaar aan met een wedde van $20 \mathrm{lb}$. 's jaars 37 . Het eerste werk van dezen grafelijken officier was de opstelling van een gans nieuw $\mathrm{ka}$ daster van 's gravenlandschuld ${ }^{38}$, de aantekening van de percelen, die tot dan toe aan de tolheffing hadden ontsnapt 39 en de opsporing van degenen, die zich aan de vereffening ervan poogden te onttrekken ${ }^{40}$. Daartoe deed hij door de schepenen van Nieuwpoort, die ook te Lombardsijde een zekere juridictie uitoefenden, een verordening uitvaardigen bestraifende met een boete van $10 \mathrm{lb}$. al degenen, die de door hen bezette percelen in den steek lieten ${ }^{41}$. De opbrengst van 's gravenlandschuld op deze wijze geind bedroeg in 1313, volgens het door den tollenaar opgemaakte kadaster, $130 \mathrm{lb}$. 0 s. 5 d. te Nieuw. poori ${ }^{42}, 7 \mathrm{lb} .13$ s. $1 \mathrm{~d}$. in de Nieure IJde ${ }^{43}$ en $62 \mathrm{lb}$.

(37) « Comptes de le cense dou tonliu de Noefport fait cest an par Pierron dou Lien, qui le tient a volonte de par monsegneur le conte de Flandre et entra el dit toniiu a le Nativite Saint Jehan Baptiste 1 an mil CCC et douze, dont li somme est por cest an $548 \mathrm{lb} .15 \mathrm{~s}$. 3 d. »- « Item pour les wages Pieron, $20 \mathrm{lb}$. 》 - Ibidem, no 273 , rekening van 1315 .

(38) Zie hierboven, nota 6 .

(39) « Dit sijn de hofsteiden, die verwiessen ende die noit te brieve waren. als me mat mijns heren arvachtichede van Vlaenoren in 't jaer ons Heren M.CCC ende dartiene jaer inde vasterne. " Kadaster van 's gravenlandschuid van 1313. R. de BEAUCOURT de NOORTVELDE: Nieuport. Documents historiques, p. 152.

$(40)$ « Jehan Scheleward, Framelin 2 s., daernael westward toten hoeke also de strate gaet, ydel lant, ende me segghet dat es Lisebetten Stacioets ende Sijmoens van cien Uutlate ende Vramelins kinder ende Lise Paijens, ende ne es niet verclaerset. 》- 《Willem Bone 2 s., daernaer zuutward ydel lant ende onthuset also me zeide ». Ibidem, p. 151, parc 45 .

(41) « Hit es jecuert bin äer steide van der Niewerport bi schepene, die oup dien dach schepene waren, bi verzoeke van Pietre van den Leene, die tolnare was, dat so wie onthuzede iof blootte mijns here arvachticheide van Vlaendren ence niet weider huzede, dat ware oup ene boete van $10 \mathrm{lb}$. par. 》 Ibidem, p. 152.

(42) Volgens onze eigen berekening. Pieter van den Lene zelf geeft geen totaal aan voor Nieuwpoort.

(43) « Dit is de grote van der rente, die mijn here de grave hebbet oup de hofsteicien van der Niewer Hijde, verniewet in $t$ jaer ons Heren $M$.CCC ende dartiene jaer ts anders daghes na Onser vrouwen dach in Marte. 》 R. de BEAUCOURT de NOORTVELDE, op cit.. p. 153.

- "Somme over al van der Hijde van den jare.. 7 lb. 13 s. ende 1 d. 》 Ibidem, p. 156. 
17 s. 5 d. te Lombardsijde ${ }^{44}$. De heffing van de stalpenning in het laatste stadje bracht $3 \mathrm{lb}$. $14 \mathrm{~s}$. op en werd er betaald door 222 personen 45 . Al tezamen brachten beide renten dus $\pm 204 \mathrm{lb}$. s. op. Wat de totale opbrengst van den tol van Nieuwpoort gedurende dat eerste ambtsjaar van Pieter van den Leene was, hebben we niet kunnen uitmaken. Voor de volgende ambtsjaren is ze evenwel gekend. Volgens de grafelijke rekeningen bracht ze voor de periode Sint-Jansdag 1314 - Sint-Jansdag 1315 , zonder aftrek van wedden en onkosten, $548 \mathrm{lb} .18 \mathrm{~s} .3 \mathrm{~d}$. op ${ }^{46}$, voor de periode Sint-Jansdag 1315 - Sint-Jansdag 1316427 lb. 16 s. 2 d. ${ }^{47}$. Voor het halfjaarlijks termijn Sint-Jansdag - Kerstdag 1316 bedroeg de opbrengst van de « aventures» slechts 97 lb. 4 d. ${ }^{48}$. Pieter van den Leene deed zich in zijn taak bijstaan door een knecht 49 , een klerk ${ }^{50}$, een roeier ${ }^{51}$ en een vertegenwoordiger te Lombardsijde ${ }^{52}$, die allen voor hun diensten een wedde of

(44) Zie hierboven nota 4.

(45) «Somme $3 \mathrm{lb}$. ende $14 \mathrm{~s}$. par. 》 Ibiciem, p. 166. Aan 4 d. per persoon komt dat op 222 personen, naar onze eigen berekening. Zie hierboven nota 6 .

(46) Zie hierboven nota 37. Brussel. Rijksarchief. Chambre des Comptes, no 273. Grafelijke rolrekening van 1315 .

(47) « Compte de le cense dou tonlien de Noefpord fait c'est an par Pierron du Lien, qui le tient a volentey de par monseigneur le conte, et entra el dit tonlieu a le Saint Jehan Baptiste 1 an M.CCC et douze, dont li somme est par an $427 \mathrm{lb} .16$ s. 2 d. 》 Ibidem, no 274 , rekening van 1316 .

(48) "Entre compta li dis Pieron recheveur du dit tonliu de le Saint Jehan 1 an seisse jusques au Noel 1 an seisse apres $97 \mathrm{lb}$. $4 \mathrm{~d}$. » Ibidem.

(49) «Item pour le service de sen valet $4 \mathrm{lb}$. 》 Brussel. Rijksarchief. Compte de la recette des gros de Flandre, no 273 . Rekening van 1315. - «Item pour 1 vallet qui aida le tonliu a rechevoir, cest anee $9 \mathrm{lb}$. - «Item Annekin le Velmakre pour 1 warde, coes pour cou qu il aida le tonliu a rechevoir $34 \mathrm{~s}$. 》 Ibidem, no 274 , rekening van 1316.

(50) «Item pour le service de sen clerc $3 \mathrm{lb}$. 》 Ibidem no 273 , rekening van 1315 .

(51) «Item a Boye le batellier pour mener le batel monseigneur ou port pour savoir ke les nees avoient kierkie qui passoient pour une anee $6 \mathrm{lb}$. 》 Ibidem, no 273. rekening van 1315 . — « Item a celui qui mena le batiel ou havoie cest anee $5 \mathrm{lb}$. 》 Ibidem, no 274, rekening van 13.16 .

(52) « Item a Henri Monne de Lombardie une paire de bras de 5 s. pour son service. 》 Ibidem, no 273, rekening van 1315 . - 《Item a Henrys Mone qui tenoit le tonliu de Lombardie pour 2 pane de robes $5 \mathrm{lb}$. ». Ibidem, n 274, rekening van 1316. 
vergoeding trokken. Blijkbaar leverde ook deze manier van uitbating niet de gewenste resultaten op, vermits de graaf van Kerstdag 1316 af den tol opnieuw verpachtte en wel voor een periode van vier iaar tegen een jaarlijksen pacht van $580 \mathrm{lb}$. Tourse groten en met uitdrukkelijk verbod aan de pachters op die som hetzij gelijk welke onkosten in mindering te brengen ${ }^{53}$. Van Kerstdag 1320 af vertrouwde hij de inning opnieuw aan een ambtenaar toe, namelijk aan Jehan Viande. Deze boekte voor het halfjaar Kerstdag 1320 - Sint-Jansdag 1321 een opbrengst van 408 lb. 4 s. 5 d., waarin evenwel ook de inning van 's gravenlandschuld en de stalpenning van voorgaand halfjaar begrepen was ${ }^{54}$.

De graaf bekostigde op de opbrengst van zijn tol te Nieuwpoort zekere uitgaven, meer bepaald renten en pensioenen ten voordele van sommige van zijn vazallen. Aldus zien we de tollenaars in het begin van de 14 de eeuw aan Henri de Baklerod jaarlijks een som van $20 \mathrm{lb}$. als pensioen uitkeren ${ }^{55}$. Tot 1324 evenwel diende het grootste gedeelte van de opbrengst van den Nieuwpoortsen tol voor de aflossing van een «assenement» van 7.102 lb. $10 \mathrm{~d}$., die de graaf verschuldigd was aan Gillion de Herseberghe, een van zijn vazallen, die van 1309 tot 1312 als tollenaar pachter te Nieuwpoort optrad ${ }^{56}$.

(53) « Et est a savoir que Watier Hategoet, Salemoen Verdeboud et Clay Colin ont acensit ie dit tonliu a tenir del Noel 16 pour 4 ans apres suiwans caschun an pour 580 b. gros tournois, pour $101 / 2 \mathrm{~d}$. ov. parisis de Paris ov. 5 noirs Tournois pour 4 parisis a paiier 1 une moitiet a le Saint Jehan et 1 autre au Noel, tous frans a monseigneur, sans riens rabattre ne pour wiere, ne pour nulle autre cose que nus censiers rabatist onques 》. Ibidem, no 274, jaar 1316. - Zie ook no 269, jaar 1317.

(54) Zie hierboven nota 2. Ibicem, $n^{\circ} 277$, rekening van 1321.

(55) « Item a Henri de Baklerod pour se pencion a vie $20 \mathrm{lb}$. » Ibidem. no 270 , rekening ran 1306. - « Item a Henri ca Bacleroit pour se pencion dou terme dou Noel $10 \mathrm{lb}$. » - «I+em donmey pour le pencion Henri du Bacleroit $10 \mathrm{lb}$. feule monnoie valant 60 s. 6 d. » Ibidem, no 271, rekening ran 1309.

(56) " Item a Gillion de Herseberghe pour sen assenement dou terme de Noel 1 an mil 300 et 10 et dou terme del le Saint Jehan 1 an mil CCC et onse $500 \mathrm{lb}$., en rabat d une somme de seet mille cent deus livres dys Geniers, que en lui deut, del le quelle somme il est ore paies de mille seet cens cinquante livres. Demeure qu on lui doit 
Buiten den tol beschikte de graaf na 1300 ook nog over enkele andere bronnen van inkomsten te Nieuwpoort en in de Nieuwe IJde, namelijk over de opbrengst van «le mote le conte a Noef́port», van de «cange de Noefport» en van de «pasturages des biestes en le Noeuve Hide». De «mote le conte» was de hoogte in 1236 door de Nieuwpoortse bevolking als straf voor de moord op twee geestelijken opgeworpen samen met een dwingburcht, die evenvel terug afgebroken geworden was. Omstreeks 1295 besloot de ontvanger van Vlaanderen de hoogte aan den meestbiedende te verpachien, in plaats van ze tegen betaling van 's gravenlandschuld aain de bevolking te laten. Terzelfder tijd ging hij over tot de verpachting van den wissel of «cange» te Nieuwpoort. Tegen beide verpachtingen tekenden de Nieuwpoortenaars krachtig protest aan ${ }^{5 T}$. De aanbesteding liep dan ook de eerste jaren van de 14 de eeuw niet van een leien dakje. De «mote», ook nog «burg» genoemd, kon gedurende een viertal jaren, namelijk van 1302 tot 1306 , geen pachter vinden ${ }^{58}$. De 《cange» kon zelfs na 1306 voor geruimen tijd in het geheel niet meer verpacht worden en wel omdat de gemeente Nieuwpoort er zich mer hand en tand tegen verzette ${ }^{59}$. De vraag kan zelfs gesteld worden of de graaf

cinc mille trois cens cinquante deus lives dijs deniers de celui assenement. » Ibidem, no 272, rekening van 1312. - Die betalingen kunnen we volgen van 1309 tot 1321. Gillion de Herseberghe streek in 1309: $90 \mathrm{lb}$. op, in 1312: $500 \mathrm{lb}$, in 1316: $446 \mathrm{lb} .13 \mathrm{~s} .8 \mathrm{~d}$., in $131 \mathrm{~T}$ : 250 lb. parisis «petis», in 1321 : «194 lb. $18 \mathrm{~s} .1 / 2$ d. gros pour $12 \mathrm{~d}$. en $55 \mathrm{lb} .11 \mathrm{1} / 2$ d. Ibidem, no $271,272,274,269$ en 277 , grafelijke rolrekeningen van $1309,1312.1316,1317$ en 1321.

(57) «Ore est venus, sires, li recheveures et a donne une mote et terre, qui entour geist, a cense, qui est rostre, a un cie leurs combourjois, lequele mote cha en ariere a estei masonnee... - « Item sires ilz prient pour. Dieu que rous ne roeilies souffrer que tors leur soet fais conme du cange mie li recereres a donne a cense, que onques fait fu fors ore, car grant grief en venroet a eaus et peu de pourfit a vou\% ». Klaagschrift van de lieden ran Nieuwpoort van omstreeks 1300. Brussel, Rijksarchief. Trésorerie des Chares de Flandre, no 867.

(58) « Contes de le cense de le mote de Noefport, ki suit valoir 60 s. par an, si $\mathrm{n}$ en at $\mathrm{t}$ on riens rechnt 4 ans aoie. 》Brussel. Rijksarchief. Chambre des Comptes, no 270. Grafelijke rolrekening van 1306.

(59) « Compte de le cense dou cange de Nuefport, dont on soloit avoir $35 \mathrm{lb}$, par an, si ne le tient ore nus par l enpaiccement dia cias de Nuefport. 》 Ibidem, no 271, grafelijke rolrekening ran 1309 . «Compte de le cense dou cange de Noefport, qui soloit valoir $35 \mathrm{lb}$. 
die verpachting niet heeft moeten laten varen 60 . De «mote» werd ieder jaar verpacht op Sint-Jansdag (24 Juni). Haar jaarlijkse pachîprijs bedroeg aanvankelijk 3 lb. ${ }^{61}$, van 1314 af $3 \mathrm{lb} .10$ s. ${ }^{62}$ en van 1320 af 7 lb. ${ }^{63}$. De jaarlijkse pachtsom van de «cange 》 was vastgesteld op $35 \mathrm{lb}$., becirag dat éénmaal, in 1306, opgebracht werd ${ }^{64}$, De «pasturage des brestes de Nieue Hede es dunes» bestond uit duinen, weiden en schorren, die in hun geheel jaarlijks verpacht werden. $\mathrm{Na} 1302$ trad Jan Breidel, vermoedelijk dis bekende Brugse beenhouwer, als pachter op. De pachtprijs bedroeg aanvankelijk 8 lb. ${ }^{65}$. Van 1309 af

et si ne le tient on mais pour l empeechement de cheaus de Noefport. » Ibidem, no 272, grafelijke rolrekening van 1312. — « Comptes de le cense dou cange de Noefport qui soloit valoir par an $35 \mathrm{lb}$. Se 1 ont chil de Noefport empechie. 》 Ibidem, no 273 , grafelijke rolrekening van 1315 .

(60) In de rolrekeningen van de jaren 1316,1317 en 1321 wordt steecis dezelide vermelding als hierboven herhaald. Ibidem, no 274 , 269 en $27 \tau$.

(61) «Conte de le cense de le mote de Noeport fait par Henri de Diepe et fina li cense a le Nativitei Saint Jehans Baptiste 1 an M.CCC et 1, dont li somme est par an $60 \mathrm{~s}$, payet a Jeffroy par maistre Hue. » Ibidem, no 267, grafelijke rolrekening van 1301, 30 rerso. - Zie ook nota 58 hierboven.

(62) «Compte de le cense de le mote de Noeufpord fait par Hategoed. Commence et finira a le saint Jehan Bauptiste 1 an M.CCC 17 dont li somme est par an $31 b .10$ s. Paiie a Guidon, rechereur en 2 parties par le main $\mathbf{P h}$. de le spriete compt. » Ibidem, no 274. Rolrekening van 1316. - "Compte de le cense cie le mote le conte a Noefpord fait par Watier Hateghout et commenca li censse a le Saint Jehan 1 an mil CCC et 14 et dura par 3 ans, dont li somme est par an $3 \mathrm{lb} .10 \mathrm{~s}$. De cou payet a Watier de Tournay $35 \mathrm{~s}$. Parisis compt. Demeure $\mathrm{k}$ il dot $35 \mathrm{~s}$. sommeit en 1 an apres. » Ibidem. no 269, grafelijke rollekening van 1317 .

(63) « Comptes de le cense de le mote le conte a Noefport fait par Jehan le Ghous et fina li cense a le Saint Jehan l an 21 dont li somme est par an $7 \mathrm{lb}$. par. grands tornois pour $10.1 / 2 \mathrm{~d}$. Item doit il de 1 an passe $7 \mathrm{lb}$. Tout ae $14 \mathrm{lb}$. De ce paiiet a Jehan Lauwaers 4 lb. compt. Demeure $10 \mathrm{ib}$. 》 Ibidem, no 277, grafelijke rolrekening van 1321.

(64) « Contes de le cense dou cange de Noefport fait par Jehan de Usene et fina li cense a le Sainte Crois en may l an M.CCC.VI., dont li somme fu $35 \mathrm{lb}$. 》 Ibidem, no 270, grafelijke rolrekening ran 1306.

(65) «Contes de le cense dou pasturage de le Neue Hede fait par Jaquemon de Diepe et fina la cense a le Nativite Saint Jehan Baptiste 1 an M.CCC. et 1 dont li somme est par an $8 \mathrm{lb} . .$. » Ibidem, no $26 \pi$, grafelijke rolrekening van 1301 . - « Contes de le cense dou pasturage es dunes des biestes de Nieue Hede fait par Jehan Brealle, dont li somme est par an $8 \mathrm{lb}$. Encore des ans passes $22 \mathrm{lb}$. Tout cou $30 \mathrm{lb}$. » Ibidem, no 270 , grafelijke rolrekening van 1306. Zie ook hieronder noten 66 en 67 . 
evenwel kon de «warde des dunes》, de duinherder, die toen als pachter optrad, die som niet meer opbrengen. $\mathrm{H}_{4} \mathrm{j}$ bleef de door hem te betalen pacht somtijds gedurende verschillende jaren verschuldigd ${ }^{66}$. In 1321 werd besloten dat de «pasturages》zouden worden verpacht volgens een prijs overeen te komen met den ontvanger van Vlaanderen 67 .

De verschillende grafelijke domeinen te Nieuwpoort en omgeving werden somtijds door een en denzelfden pachter in uitbating genomen. Aldus zien we in 1301 Jacquemon de Dieppe tegelijk de «tonliu de Noeport» en de «pasturages» van de Nieuwe IJde in pacht nemen, terwijl zijn broer, Henri de Diepe, de «mote» te Nieuwpoort voor zijn rekening nam ${ }^{68}$.

In 1324 kwam her grafelijk domein te Nieuwpoort samen met de stad als apanage in het bezit van Robert van

(66) « Compte de le cense dou pasturage des biestes de le Nieue Hede es Dusnes, feit par le frere mestre Nicholon le Felitien, warde des Dusnes, feit par le frere mestre Nicholon le Felitien, warde des cusnes, dont li somme est far an $8 \mathrm{lb}$. bonne monnoie. Encore doit il des ans passeis vint et quatre $\mathrm{lb}$. foinle monnoie, valent $8 \mathrm{lb}$. bon. Toute ce $16 \mathrm{lb}$. bonne momnoie. Et est a savoir que Jehans Bredele doit d arrierages de le ditte cense pour le tans $\mathrm{k}$ i fu warde des dune:s. si comme en le reneghiele en 1 an M.CCC. et cuinch faite apirt 22 lb. feule monnoie. 》 Ibidem, no 271, grafelijke rolrekening van 1309. Dorzaak van de insolventie was heel waarschijnlijk de voortdurende zandverstuiving en vorming van nieuwe Gainen. Zie ibidem, no 267 , grafelijke rolrekening van 1301. Tekst hierboven nota 18, p. 86.

- «Compte del le cense dou pasturage des bestes en le Nieuwe Hide es dunes faite par Jaquemon delle Pierre, warde des dunes, dont li somme est par an $10 \mathrm{lb}$. Item doit il des ans passeis $30 \mathrm{lb}$. Tout ce $40 \mathrm{lb}$. sen rechut pour le terme avec fouile monnoie. Ensi ne doit il que $33 \mathrm{lb} .6$ s. 8 d. forte monnoie, mis en 1 an apres. Et est a savoir que Jehan Bredel doit d arrierages del le dite cense pour le tans qu i? fu garde des dunes, si comme en li renenghiele del an mil trois cens et cinc apert $22 \mathrm{lb}$. feule monnoie, mis en 1 an apres. 》 Ibidem, no 272. grafelijke rolrekening van 1312. - Voor de volgende jaren zie de grafelijke rolrekeningen van 1315, 1316 en 1317. Ibidem, no 272. 274 en 269.

(67) « Compte de le cense du pasturage des biestes en le Nieuwe Heide des Dunes fait par Widot le Crane qui en coit rendre compte pour ceste annee. car il a manyet le dit pasturage. Et est a savoir que Guiduce Baldecon y a prise le dite cense et en doit payer cou que mesire Willames del Acke, Colars de March et Simons, recheveurs en ordeneront... » Ibidem, ro 277, grafelijke rolrekening van 1321.

(68) «Conte de la cense du tonliu de Noeport par Jaquemon de Diepe 1 an et le jour et au liu ciessus dis, dont li somme est par an $5801 \mathrm{~b} . . . . \gg$ Ibidem, no 267 , grafelijke rolrekening van 1301 . - Zie ook nota 61 en nota 65 hierboven. 
Kassel. Na zijn dood ging het over, eerst aan zijn vrouw Johanna van Bretagne, daarna aan zijn dochter, Yolande van Bar, die het tor 1350 kon behouden ${ }^{69}$. Welke dan de wijze van uitbating was, hebben we nier kunnen na. gaan. Wat er ook van zij, toen graaf Lodewijk van Male in 1350 zich opnieuv in het genot van zijn prerogatieven te Nieuwpoort stelde, was zijn eerste werk er ridder $\mathrm{Hu}$. ghe van Halwyn als «rewaeri, ontvanghere ende bailliu» heen te sturen 70 .

Cnder de regering van Lodewijk van Male was de gewone uitbating van den tol van Nieuwpoort wederom de verpachting. Dit systeem gaf evenwel nogmaals aanle:ding tot misbruiken en moeilijkheden. De Nieuwpoortse tollenaars kwamen in 1373 en 1375 in conflict achtereenvolgens mat de burgers van Sint-Omaars $i 1$ en met de

(69) J. J. CARLIER, ROBERT de CASSEL, in Ann. Com. flam. de France, année 1868-'69, p. 128, P. I. no IV. - M. DE SMYTTERE : Essai historique sur Folande de Flandre, comtesse de Bar et de Longueville. Lille, 1877. - J. FINOT : Inventaires sommaires des Archives départementales du Nord, série B, t. VII (1892), p. XXXII-LIII.

(70) « Nous Loys, ete, faisons savoir a tous. que nous avons mir et establi, mettons et establissons nostre ame et feal cheralier, messire Hue de Hlawin, nostre rewart et rechereur de la ville et chastellenie de Berghes Sente Winnoc et de la ville die Noefpoort et de toutes les appendances et appertenances, auquel nostre dit chevalier. nous avons donne et dounons plain pooir, auctorite et mandement especial en nostre nom et pour nous des dictez rilles et chastellenie, avoeques toutes leur appertenances comme nostre propre heritage mettre en nostre main de tous biens, rentes, revenues, explois et aultres quelconques a ycelles villes et chastellenie appartenant exploi tier, rechevoir et lever a rostre ees, de ent quitter et warandir, de rechevoir en nom de nous feautes de tous les hommes de fief as cessus dictez villes et chastellenie appendans...» Oorkonde ran 5 Augustus 1350. Th. de LIMBURG-STIRUM : Cartulaire de Louis de Male. Bruges, 1898-1901, t. I, p. 174, no CLXXIV. - Zie ook ibidem. no CLXXXIV. Oorkonde van 11 Augustus 1350. Zelfde oorkonde, maar in Vlaamse tekst. - In de grafelijke rolrekening van 1351 blijft de rubriek « Compte de le chense dou tonliu de Noefport » vooralsnog oningevuld. Brussel. Staatsalchief. Compte de la recette des gros de Flancire, no 282.

(71) «De zaken van den besouke tusschen den tholnars van der Niewerpoort ende dien van Sinte Omars oin $t$ occoisoen van den tholle daenof die van Sinte Omars vry waren willen : Sijn uutegheset toter naester audiencie, sdaech naer sinte vincencisdach ». N. DF PAUW : Bouc van der Auliencie, op cit,, p. 510, no 1119. - Zie ook ibidem, p. $545, n^{\circ} 1165 ;$ p. 496, no 1046. Data van de twee eerste teksten : 12 December 1373 en 29 Januari 1374. De derde tekst is de oudste en leidt het gecoing in : ze dagtekent van 21 Augustus 1373. 
lieden van Veurne-Ambacht ${ }^{72}$, van wie ze zonder recht op het transitoverkeer tollen dierven eisen. Beide geschillen kwamen voor de Audiencie of grafelijken rechtbank. Alleen de uitspraak in het tweede geschil is gekend. De tollenaars werden in December 1375 tot de betaling aan de grafelijke schatkist van een boete van $300 \mathrm{lb}$. veroordeeld, terwijl de lieden van Veurne-Ambachr hun oud voorrecht van gedeeltelijken tolvrijdom bekrachtigd zagen 73 . Het volgende jaar kwamen de tollenaars in twist met de keurbroeders van Poperinge, van wie ze eveneens onwettige tollen eisten. Dit maal gold het evenwel lieden, die geen tolvrijdom genoten ${ }^{4}$. Ook dit geschil kwam vóór de Audiencie. Hoe het beslecht werd, hebben we niet kunnen uitmaken.

Lodewijk van Male bekostigde evenals zijn voorgangers op den tol van Nieuwpoort enkele renten, waaronder één ten bedrage van $150 \mathrm{lb}$. ten gunste van heer Wulfard van Gistele en één ten bedrage van $300 \mathrm{lb}$. ten bate van de Franse hospitaalridders of ordebroeders van Sint Jan van Jerusalem, wier lenein in Vlaanderen hij afgekocht had. De eerste was etn lijfrente verleend in 135775 . De tweede integendeel was een voorlopige rentebelegging door over-

(72) «Tusschen die van Veurn-imbocht an d eene zide ende den tholnars ran der Niewerpoort an d andere van dat de tholnars thol hebben ende heffen willen van cuerbroeders in Veurn-Ambocht van scepen die uit Veurn-Ambocht vor de havene te Niewerpoort in de zee varen, die men heet zeelopers, van den goede datter ingheladen es, nochtans dat zij $t$ goet te Niewerpoort laden noch ontladen, daerof die van Veurn-Ambocht vry sculdech sijn te stane, also zij segghen, daer of de tholnars de contrarie segghen. 》 N. DE PATTW. Op cit., p. 672, no 142 $\tau$. Tekst van 29 Januari 1375 (no XXXV).

(73) Ibiciem, p. 809. no 1713, tekst van 10 December 1375 (XI,I). Rijsel. Arch. dép. Gur. Nord. Inventaire som. nouv., p. 174.

(74) N. DE PAUW. Op cit., p. 871 , no 1826 , tekst van 8 Juni 1376 (XLIV). - p. 941, no 1969, tekst van 26 Januari 1377 (XLVIII).

(75) « Gheren den vorseiden mer Wulfard hondert ende viftich pond parisis siaers onser munten van Vlaendren, als langhe als hi leven zal, te heffene ende te ontfane up onsen thol van der Nieuwerpoort, te tween terminen siaers : deene heilt te middewintere, ende d andere heilt te Zente Jans messe mitszomers... » Th. ¿e LIMBURGSTIRUM: Cartulaire de Louis de Male, op. cit., t. II, p. 81, no DCCXCII. Oorkonde van 3 Augustus 1357. 
eenkomst in 1365 aangenomen en waarvoor de burgemeesters en de schepenen van de gemeente Nieuwpoort zich borg hadden moeten stellen. Hun taak bestond er in jaarlijks van de tollenaars de rente te vorderen en aan den grootprior van de orde uit te keren. Gelukkig voor de Nieuwpoortse wethouders en gemeente was de rente slechts een tijdelijke belegging in afwachting, dat de graaf, om de montiken voliedige voldoening te schenken, haar definitief in Frankrijk zelf kon beleggen, wat vermoedelijk nog vóór 1383 gebeurde ${ }^{i}$.

In 1384, bij het overlijden van Lodewijk van Male, ging 's graven domein te Nieuwpoort en omgeving ten slotte over in de handen van de Bourgondische hertogen.

Al deze gegevens tezamen, laten ons toe, altans voor de $14 \mathrm{e}$ eeuw, een denkberid te vormen van de opbrengst van den Nieuwpoortsen tol. De gemiddelde jaarlijkse pachtprijs zijnde, ten minste gedurende de periocie 1300 1324, zowat 500 à $600 \mathrm{lb}$, mogen we aannemen, gezien 's gravenlandschuld zowat $200 \mathrm{lb}$. opbracht, dat de tol op de handelsverrichringen te Nieuwpoort ieder jaar ongeveer 300 à $400 \mathrm{lb}$. opleverde, wat voor dien tijd niet te versmaden was. Dit bewijst meteen ook het belang van Nieuwpoort als inooppuni van de handelswegen in het IJzerbekken $i \tau$.

\section{R. DEGRYSE.}

(76) « Donnans aussi en mandement par ces presentes as censiers de notre dit thonlieu qui sont et seront et a ceuls qui auront la recep:e dou dit tonlien en mains et a cestiu d eulz que reues ces lettres, qui demourront a ta ville de Noefport, il se oblegent a la ville de Noefport par leurs lettres a paier et paient d an en an et de terme (n) terme dessus dit durant leur cense et leur maniance la dite somme de trois cens lirres parisis par an as borchmeestres et esche vins de Noefport pour la cause et en la maniere dessus dites... » Nieuwpoort. Stadsarchief. no 198 (charter $\mathrm{n}^{\circ} 21$ ). Oorkonde ran 12 Juni 1365, naar een eerste vidimus ran 28 Juni 1365 en een tweede van 17 Februari 1385 (nieuwe stijl).

(77) R. DEGRYSE : Oude en nieuwe havens van het IJzerbekken in de Middeleeuwen $\gg$, in Handelingen van de Soc. d'Emulation van Brugge. Deel 84 (jaargang 1947), pp. 6-40 (p. 21). 


\section{BIJLAGEN 1}

\section{I}

September 1241. - Oorkonde waardoor gravin Johanna en graaf Thomas afstand doen van bepaalde rechten hen toegewezen te Nieuwpoort door een scheidsrechterlijke kerkelijke commissie in de zak van de moord op twee priesters en waardoor ze terzelfder tijd eveneens afschaffen de tollen, die te Nieuwpoort drukten op de schuiten en de voertuigen, die in dienst van de burgers van deze stad, goederen aanvoerden of uitvoerden. - Kopie van een verloren stuk. Rijsel. Archives départementales du Nord, B.1373 (729).

Copie de privileges de Neufport. -

Premiers du privilege du conte Thumas, qui quite ceulx de Neufport $4 \mathrm{~d}$. de chacun car et charette et deux deniers de chacune schute y apportant biens, qu ilz souloient paier par ma. ntere de tonlieu et que li transgresseur payera double amende.

Nos Thomas comes et Johanna uxor nostra, comitissa Flandrie et Haynonie, notum facimus universis presentes litteras inspecturis quod scabinos et communitatem de Novoportu quitavimus et absolvimus de omni eo quod nobis fuerat adjudicatum in arbitrio quod erat inter ipsos ex una parte et capitulum Beate Walburgis Furnensis ex altera, videlicet de morte presbiterorum. Preteres sum apud Norumportum exigeantur quatuor denarii de curru et de biga deferente bona cujuscumque de quibus theloneum debitum est solutum et de scutis afferentibus bona illorum de Novoportu ibidem duo denarii exigantur. Nos intelligentes hoc esse pocius exactionem quam debitum, ipsos de dictis quatuor denariis de curru et de biga et de duobus denariis de scutis in perpetuum quitamus et absolvimus pro nobis et successoribus nostris. Concedimus eciam eisdem et volumus de litigantibus quod insultor convietus ad legem solvat pro utroque. In cujus rei testimonium presentes litteras sigillis nostris duximus roborandas. Actum anno domini $\mathrm{M}^{\circ} \mathrm{CG}^{\circ}$ quadragesimo primo mense septembri.

(1) Ik dank hierbij de hh. P. de Saint-Aubin (Rijsel), Prof. Dr. Hans Van Werveke (Gent) en de diensten van het Algemeen Rijksarchief (Brussel) voor de hulp, die ze mij bij het collationneren van deze Bijlagen geboden hebben. 
II 1

16 Oktober 1274. - Oorkonde waardoor gravin Margaretha aan de abdij Sint Pieter te Oudenburg een stuk moer te Aardenburg schenkt in ruil voor de gronden, waarop ze het nieuw stadje Lombardsijde had doen oprichten en die feitelijk aan deze abdij toebehoorden. - Videmus van 4 November 1293, gegeven door de abten van Sint Andries te Brugge en van Sint Bartholomeus van den Eeckhoutte. Gent. Rijksarchief. Fonds de Saint-Genois, $\mathrm{n}^{\circ}$ 194. - Dergelijk vidimus bevindt zich ook te Nieuwpoort in het stadsarchief in het dossier $n^{\circ} 2919$.

Universis presentes litteras inspecturis, Petrus et Johannes, divina permissione abbates Sancti Andree iuxta Brugis et sancti Bartholomei de Echout, salutem in domino. Noverit universitas vestra nos vidisse privilegium Margarete comitisse Flandrie et Hannonie et Guidonis eius filii, comitis Flandrie et marchionis Namurcensis, non abolitum, non cancellatum, nee in aliqua sui parte viciatum in hec verba: Nous, Margherite contesse de Flandres et de Haynau faisons a savoir a tous, ke comme nos eussiens iadis faite et estoree nostre vile de Lombardie daleis notre port de Noefport et ke nous a ceaus de celi vile de Lombardie eussiens dounei masures partie es dunes $u$ il ont maisonnei, et partie seur le hem vers Noefport, dont nous avons ades puis receues et recevons les rentes. Et comme li abes et li couvens de Audembourg se plainsissent devant nous souvent, ke nous cel vile aviens estoree et les masures dounees tout seur le leur, c est a savoir en partie seur lor pasture, qu il ont es dunes dou don de nous ancisseurs et en partic seur le hem ke est lor iretages par le don de nos ancisseurs ausi, si omme il apeirt par lor chartes, nous envoiames religieus home, I abei de Saint Nicholai de Furnes t Michiel chanonie de Furnes, nostre clerc, pour enquerre de ces choses au liu devant dit. Et nos raporterent li abes et Michius devant nommeit ke dehors le liu $\mathrm{u}$ li vile est maisonee, nos gens avoient dounei a ceaus de Lombardie, pour masures, seur le pasture de ceaus de Audembourg treinte et cuinc mesures, douse verges mains; es rues sis mesures, deus lignes et trente verghes, et seur le hem, ki hiritages

(1) Nota van den heer Prof. Dr. Hans Van Werveke : in dit stuk is er een moeilijkheid in verband met den term « couvens ». Er staat wel degelijk telkens « u », terwijl men in dien tijd gewoonlijk « conrens » schrijft. Maar nu staat er eveneens in den tekst « encouvent », waar het natuurlijk « enconvent » moet luiden. Il rraag me dan ook af of « couvens 》 niet in « convens » zou mogen veranderd worden. 
est de 1 Eglise de Audembourg, quinze mesures, ciunquante verges et en rues quatre mesures, et ke de ce nous avons reciut ef recevons les rentes. El nous en restor de ces choses devantdites avons dounei et dounons al abei et au couvent de Audembourg devant dis quatre bouniers de nostra moer de Rodembourg a tout le tresfons gisans seur le waterganc ke on apele watergane segneur Jehan en coste le moer dame Margherite, veve segneur Pol le Calcre, le viel, et tout une voie ki a a nom vakewech, ki contient dis et wit verghes de moer de long et trois verghes, dis pies it demi de large pour le valeur de trois cens livre de nostre monoie de Flandres, lequel moer nous lor avons fait delivrer par Dant Eustacie, maistre de Stoppeldike, et par frere Jehan, maistre de Groude, a tenir de nous et de nos hoirs apres nous, segneur's de Frandres, parmi noef deniers de cens de le monoie de Flandres pour chascun bounier a paier chascun an a le Saint Remi as bries de nostre moer de Rodembourg. Et parmi ce li abes et li couvens devant dit ont cuitei a nous et a nos hoirs, segneurs de Flandres, tout ce ke nous en avons receu et tout ce ke cil de Lombardie en tienent ore et dont il paient rente a nous, selon 1 enqueste, ek li abes ef Michius deseure dit nos raporterent. Et volons ke tous li remanans dehors ete en iretage et en pasture demeurt a tousjour's mais a 1 Eglise de Audembourg selonc la teneur de chartres, qu il en ont de nos ancisseurs. En tesmoignage et en confirmance de laquel chose nous avons dounei ces presentes. lettres a $\mathrm{l}$ abei et a couvent de Audembourg souvent nommes, seelees de nostre seel. Et je Guis, fius a la noble contesse devantdite, cuens de Flandre et marchis de Namur le cuitance, le confirmance et toutes les choses devantdites, tout ensi ke ma chiere dame et mere devant nommee, les a faites cuitees et confirmees, les loe gree et approeuve et les permet, et ai enconvent loiaument a tenir et a faire tout entierement par moi et pas mes hoirs apres moi segneurs de Frandres, tout en si ke devant est divisei perpetuement. En tesmoignage et pour seurtei de la quel chose je ai fait metre mon seel a ces presentes lettres, ki furent donees en I an de I incarnation nostre segneur Jhesu Christ M.CC. soissante et quatorze, le mardi des octares Saint Denise. In quorum omnium testimonium et munimem presentibus litteris sigilla nostra duximus apponenda. Datum anno domini M.CG.XCIII dominica infra octavas Sancti Martini hiemalis.

Registrata est

de la vile de Lombardie 


\section{III}

18 Decembe: 1290. - Gwijde van Dampierre, grauf van Vlaanderen, stelt ter beschikking van de gemeente Nieuwpoort en wan de parochie can sint Laurentius 12 gemeten gronds liggende limnnen de stad en dect uitmakende lan het «Portelant», met de verpuchting tot oprichting aldaur can een stedelijh en parochial hithihof o't ongeveer / gemet oppertakte. - Rijsel. Archives départementales du aord, B. 1371/568. Kopic in veertiendeeuws geschrift van cen verloren oorkonde.

Guido comes Frandrensis et marchio Namurcensis universis presenies liltaras inspecturis et specialiter reverendo in Christo patri J. dei gratia episcopo Morinensis, salutem in domino. Noverit universitas vestra quod nos utilitate et necessitate ecclesic et ville nostre Noviportus consideratis et attentis, ipsi ville et ejusdem parrochiali ecclesic propter Deum et pietatis infuitu, concedimus et donamus unam plateam seu peciam terre duodecim mensuras vel cerciter continentem, sitam in dicta villa ad locum qui dicitur Portelant deo dedicandum et ad faciendum in eadem platea cimiterium ad opus ville et ecclesie predictarum, et volumus quod dicta platea continens in se quantitatem unius mensure terre vel circiter ex quo per manu episcopi be. nedicta fuerit plena imperpetuum cimiterii gaudeat libertate. In cujus rei testimonium presentibus sigillum nostrum duximus apponendum. Datum anno domini millesimo ducentesimo nonagesimo feria secunda ante festum beati Thome Apostoli.

Item copie des lettres de Guy, conte de Flandre, qui amortist. une mesure de terre, la ou li moustiers Saint Leurens en la ville de Nieuport sict, et se y donne 12 mesures de terre (1).

\section{IV}

Dmstreeks 1295. - rilaagschrift waarin de lieden van Nieuwpoort hun grieven in zake het grafelijk domein in hun stad uiteenzetten. - Brussel. Rijksarchief. Trésorerie des Chartes de Flandre, $n^{\circ} 867$.

A vous, tres haus, gentieus et tres ames sires, pourveaules princes, sires, cuens de Flandres, apres nostre singneur leur sin. guleur singneur, monstrent li boene gent communaument de Nuefport, vostre humele obeissant, et prient pour Dieu et misericorde a vous et a vostre discret consael, que vouz vos humeles

(1) Rugnota. 
orelles et droituraule cuer, voellies doneir as poins qui chi s en siewent, que nostre sires vous en sache grei et que il joiissent du droit.

Tres poissans sires ir vous monstrent, que cha en ariere des vos combourjcis de Nuefport eet autre de dehors, qui le leur furent, tres poissant que il douz sires, a le fie ont este eschevins et tonlier et a la fie bailliu et tonlier ensamble, qui le tonlier accensirent et bien sires, il ont en leur pensee et cuer, que nus tors ne desraisons ne leur fu accensiet et sont venu i cil outre, ce de leur forche, sans connoissanche de Dieu, ne de sa glorieuse meire et les ont a tort meneis et tort d eaus pris, contre leur privileges et droet en un point especiaument plus des autres, qui tens est. Et ce est, qu il voelent prendre et ont pris de un tonnel de cervose d Engleterre et d autre estrainge servose 1 argent de quatre les ou il ne deusent de droet prendre que denree, sires pour dieu merchi, ceste forche et torts, se diex plaist et le droet, vous ne soufferreis mie, car adeis il 1 ont calengiet, dont il prient pour Dieu et misericorde, que vous les faites tenir a droet et que on faiche trois brief et que on meche le un ou moustier, I autre en le hale et le tiers ou ghiselhus, si que cascuns puisse sancer qu il doet.

Item sires, il vous monstrent de un autre point, qu il eut de anchienete bien use, qu il peusent prendre et ont pris les terres du singneur geisans en le banliewe do Nuefport pour le pourfit du commun pour le droet du singneur, c est le maisure pour deus solz laen et en le mesure de terre en a douse et demie, c est le mesure vint et cinc solz. Ore est venus sires li recheveures et a donne une mote et terre, qui entour geist a cense, qui est vostre a un de leurs combourjois, lequele mote cha en ariere a estei masonne. Et sires, se vouz le vausisies masonneir, il en seroient lie et joiant, et puis que vous ne le voleis masonneir et uns autres le maisonne, si prient il con leur donne selonc leur boen usage pour le commun pourfit de le ville, et sires si comme il leur samble, uns communs pourfis doet aleir et miex valoer de une singuliere personne, et sires, si comme il entendent, pirs vous enleveries de le ville que de le convenenche faite, $\mathrm{s}$ en voellies pour Dieu teil avis que nostre sires vous en sache grei.

Item sires, il vouz prient pour Dieu, due vous ne voellies souffrer, que tors leur soet fais, commc du cange, que li receveres a donne a cense, que onques fait fu fors ore, car grant grief en venroet a eaus et peu de pourfit a vouz.

Ce sont li grief ceus de Nerufport 1 .

(1) Rugnota. 